ISSN: 0212-0267

DOI: http://dx.doi.org/Io.I420I/hedu20I83769II4

\title{
EDUCACIÓN, MOVIMIENTO OBRERO Y SINDICALISMO (ESPAÑA, SIGLO XX)
}

\section{Education, the labour movement and trade unionism in $20^{\text {th }}$ century Spain}

\author{
Aida Terrón \\ Universidad de Oviedo \\ Correo-e: aterron@uniovi.es \\ Antonio VIÑAO \\ Universidad de Murcia \\ Correo-e: avinao@um.es
}

Recepción: 20 de mayo de 2017. Envío a informantes: 6 de junio de 2017

Aceptación definitiva: is de julio de 2017

RESUMEN: Este artículo trata sobre las relaciones entre el movimiento obrero y la educación formal, así como sobre la génesis y evolución del sindicalismo docente. Primero, se exponen las propuestas y acciones educativas del anarquismo libertario y el socialismo durante el primer tercio del siglo xx y la Guerra Civil. Se analizan, particularmente, sus actuaciones dirigidas a establecer una red escolar propia, así como la influencia que ejerció el sistema educativo soviético como modelo a seguir o, por el contrario, a rechazar. Posteriormente, se analizan el resurgir del movimiento obrero durante el franquismo (1950-1977), la aparición del movimiento de enseñantes (1968-1977) y la recomposición del sindicalismo docente. En este contexto se da cuenta de la propuesta de «alianza entre las fuerzas del trabajo y la cultura», propugnada por algunas fuerzas políticas, y de los debates sobre la caracterización de los docentes como trabajadores de la enseñanza, así como sobre las alternativas educativas surgidas en 1975 -1977 y su naturaleza entre reformista y revolucionaria.

Palabras Clave: educación; movimiento obrero; sindicalismo; España siglo xx.

АвSTRACT: In essence this article explores the relationship between the labour movement and formal education and the origins and development of teaching 
unions. The first part presents the educational proposals and actions implemented by the libertarian anarchist and socialist movements during the first thirty years of the $20^{\text {th }}$ century and then, during the Civil War. It further examines the steps taken by these movements to set up their own schooling network, and the influence exerted by the Soviet education system of the time-either as a model to follow or, on the contrary, one to reject. In the second half, the article assesses the role played by the resurgence of the labour movement under Franco's dictatorship (1950-1977), including the rise of the teacher movement (1968-1977), and, finally, the reconfiguration of the teaching unions. It is in this context that the article considers the proposal of «an alliance between the forces of labour and those of the arts", as advocated by certain political groups, including the then current debate about the designation of teachers as educational workers, as well as the 'Educational Alternatives' that flourished between 1975 and I977, the nature of which was both revolutionary and reformist. Spain.

KEY wORDs: education; the labour movement; trade unionism; $20^{\text {th }}$ century

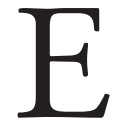

STE ARTÍ́CULO REQUIERE ALGUNAS CONSIDERACIONES PREVIAS. La primera es que no pretende llevar a cabo un estado de la cuestión acerca del conocimiento e investigaciones sobre el movimiento obrero y la educación en la España del siglo xx. De ahí que defraude a quienes lo lean esperando hallar en él una más o menos exhaustiva bibliografía sobre el tema. Son muchos los trabajos existentes que no serán mencionados sin que ello suponga que no se les ha tenido en cuenta. No hay reparo alguno en reconocer lo que el artículo debe a publicaciones de especialistas en el tema como Francisco de Luis Martín, JeanLouis Guereña, Alejandro Tiana, Pere Solà, Luis Miguel Lázaro, Marta Jiménez, Paloma O’Malley o Tamar Groves -entre otros, además de los trabajos de Aida Terrón sobre asociacionismo y sindicalismo docente-. Simplemente, constituye una reflexión personal sobre una serie de cuestiones que atañen a las continuidades y cambios que se advierten en el movimiento obrero en sus relaciones con la educación en la España del siglo xx.

De entre las posibles cuestiones a tratar, dejamos fuera de nuestro análisis las posiciones, estrategias y acciones del movimiento obrero en el campo de la educación informal y, sobre todo, de la cultura, así como las relativas a la formación sindical y profesional realizada por los sindicatos «de clase», aunque se aluda en ocasiones a ambos temas. Nos centraremos sobre todo en la posición, estrategias y acciones de las sociedades, sindicatos y partidos obreros en relación con el sistema educativo formal y con otros movimientos sociales -sobre todo, los vecinales y de enseñantes-, y los debates planteados en dicho movimiento acerca de las relaciones entre trabajo manual e intelectual -o entre obreros e intelectuales, profesionales y técnicos- ${ }^{-}$. Una cuestión en la que se inserta, a su vez,

- Un tema, el del papel de los intelectuales en el movimiento obrero que aparecerá una y otra vez desde la génesis del mismo, y que constituirá el principal leitmotiv de la obra gramsciana. Véase, 
el debate sobre la discutida caracterización, o no, de la profesión docente como clase trabajadora. $\mathrm{O}$, en relación con ello, el dilema entre la apertura y alianza del movimiento obrero con las fuerzas progresistas del mundo de los profesionales y técnicos y de la cultura -intelectuales, escritores, artistas-o, por el contrario, de recelo. Este tipo de cuestiones nos llevarán, asimismo, a centrar la atención en una serie de dilemas o tensiones a las que el sindicalismo docente «de clase» tuvo $\mathrm{y}$ tiene que hacer frente:

- Poner el acento reivindicativo en los aspectos ideológicos o en los profesionales, sobre todo los económicos y corporativos. Es decir, abrirse a todo un grupo social, el profesorado, por lo general carente de conciencia de clase u obrera, o solo a quienes se consideran trabajadores de la enseñanza².

- Promover un sindicato único de trabajadores de la enseñanza -unidad sindical- u optar por la pluralidad sindical y acuerdos temporales, entre los sindicatos existentes, sobre cuestiones o acciones concretas.

- Integrarse en un sindicato obrero formando, o no, una sección específica dentro del mismo, o constituir un sindicato de enseñanza independiente.

Las continuidades y los cambios apreciables están marcados con un antes y un después por la Guerra Civil y la dictadura franquista, así como por acontecimientos externos tales como la revolución rusa y la configuración en los años veinte y treinta del sistema educativo soviético. $O$, de forma incipiente en los años sesenta y plena en los ochenta, por la progresiva inserción del sistema educativo español en diversos organismos internacionales, y la generalización de la educación básica entre la clase obrera y su integración en una sociedad donde el consumo, los medios de comunicación y la industria cultural constituyen instrumentos básicos de formación de las mentes y de las conciencias.

\section{Movimiento obrero y educación en el primer tercio del siglo xx}

Desde sus orígenes, ya en el siglo xIx, el movimiento obrero toma conciencia: a) de las carencias de las clases populares en materia de instrucción o educación formal; b) de que esta última constituye un privilegio de las clases medias y altas; y c) de la necesidad de crear «sus» escuelas para las clases populares, así como centros instructivos y culturales propios. La educación integral, laica y racionalista

por ejemplo, Gramsci, Antonio: La alternativa pedagógica, Barcelona, Nova Terra, 1976, en especial pp. 55-76, y su conocida consideración de «todos los hombres» como «intelectuales»-aunque no todos tengan «en la sociedad la función de intelectuales»- reconociendo la existencia de «un mínimo de actividad intelectual creadora» en todo «trabajo puramente físico» y negándose a separar al «homo faber del homo sapiens» (pp. 6o-6I).

2 Javier Doz, primer secretario general de la Federación de Enseñanza de Comisiones Obreras entre 1978 y 1989, afirmaba, desde el realismo pragmático, que «para que el sindicalismo de clase sea mayoritario en la enseñanza: primero sindicalistas, después de clase» (Doz, Javier: «De la fundación a ... la huelga del 88», en 20 años de sindicalismo de clase, trabajando contigo, Madrid, Comisiones Obreras, 1998, pp. 2-9 (p. 9). 
sería el modelo educativo propugnado por el movimiento obrero y compartido con republicanos y librepensadores. Pero en su seno, también desde el comienzo, surgen dos modelos, con sus redes diferenciadas física, ideológica y organizativamente: la anarquista-libertaria y la socialista.

\section{I.I. El modelo anarquista-libertario}

La posición general del anarquismo en relación con la educación es conocida: se rechaza la escuela estatal o pública y se opta por la construcción de una red escolar y formativo-cultural propia ya desde la constitución de la Sección regional española de la Primera Internacional en I870. Como se diría en I873 desde el Boletín de la Federación Regional Española de la Primera Internacional,

la instrucción que nos conviene a nosotros y en general la instrucción de toda clase debemos proporcionárnosla nosotros mismos, porque el Estado supremo conservador de privilegios y monopolios, tiene acaparados todos los medios dispuestos solamente para aquellos que poseen capital, esto es para los parásitos y explotadores ${ }^{3}$.

En igual sentido se había pronunciado el Dictamen emitido en el III Congreso Obrero celebrado en 1872 en Córdoba sobre los «Medios para establecer escuelas puramente internacionales en el mayor número posible de poblaciones». Tras rechazar la «enseñanza que en la presente sociedad se difunde, [...] emponzoñada por el virus autoritario, clerical y burgués -fuerza, farsa y explotación- muy útil para [...] hacer al hombre esclavo del hombre, intelectual, política y económicamente», se propone la creación de escuelas en los locales de las distintas federaciones, correspondiendo a ellas establecer el plan de enseñanza; utilizar como libros «los periódicos y folletos internacionalistas», y recurrir, como profesores, a los obreros que, sabiendo «un poco», pueden y deben «enseñar a los que saben menos»4.

Los principios ideológicos de esta red de centros educativos serían, en contraste con los de la escuela «burguesa», privada o estatal, los de una enseñanza integral -un concepto, de origen bakunianos, objeto de debate y clarificaciones no siempre acordes $s^{6}$, laica, racionalista, científica -fe en la ciencia como instrumento de emancipación y liberación- y antiautoritaria, que fuera el origen de un hombre nuevo y de un orden social basado en la libertad frente a los poderes políticos y religiosos y la inexistencia de explotadores y explotados.

Tres aspectos nos interesan del anarquismo en relación con la educación. Uno es su antiestatismo. En el segundo congreso de la Confederación Nacional del

Boletín de la Federación Regional Española, Alcoy, 6, 20, febrero, 1873, pp. 86-89.

4 Lázaro Lorente, Luis M.: La Escuela Moderna de Valencia, Valencia, Consellería de Cultura, Educación i Ciència, I989, p. 54.

BaKunin, Mijail: La instrucción integral, Barcelona, José J. de Olañeta, 1979 [1869].

6 Tiana Ferrer, Alejandro: «La idea de la enseñanza integral en el movimiento obrero internacionalista español (I868-I88I)», Historia de la Educación, 2 (I983), pp. II3-I2I, y LÁzARo LorenTe, Luis M.: La Escuela Moderna..., op. cit., pp. 51 y ss. 
Trabajo (CNT), celebrado en diciembre de 1919, uno de los temas planteados fue el de la adscripción o no de dicho sindicato a la Tercera Internacional comunista creada ese mismo año por iniciativa del partido bolchevique y, junto a ello, el de la posición anarquista ante la revolución rusa. El «gran derrotado» del congreso sería, según Gómez Casas, Eleuterio Quintanilla, un exchocolatero, profesor desde igis de la Escuela Neutra Graduada de Gijón fundada en I9II, de la que llegaría a ser director 8 . Para Quintanilla, como para otros anarquistas, la Revolución rusa podía «suscitar las simpatías obreras», pero no era obra de una "organización sindical, sino de un partido que implantó un gobierno revolucionario», lo que implicaba una «concepción centralista que mediatizaba la intervención definitiva del pueblo en los movimientos revolucionarios», es decir, «una dictadura estatista»?.

El otro aspecto es su concepción autogestionaria -con su versión autodidacta en el plano individual- de la sociedad y de la educación. Una concepción que explica la índole asistemática de la red escolar anarquista, a cargo de maestros con o sin título y financiada de forma independiente por ateneos obreros libertarios, el sindicato anarquista (CNT), creado en I9II, y por cuotas de los padres. O el fracaso, en este caso también por la represión posterior, del intento de crear «una Escuela normal nacional, destinada a perfeccionar los conocimientos de los compañeros con nociones de pedagogía, o a discípulos aventajados salidos de las escuelas racionalistas $»^{\circ 0}$, con la consiguiente «falta de maestros para todas las escuelas» anarco-libertarias abiertas durante los años de la Segunda República ${ }^{\text {II }}$.

El tercer aspecto es la renuencia inicial del movimiento educativo anarquista a incorporar las enseñanzas de tipo técnico-profesional o, si se prefiere, de índole manual. Había dos razones que justificaban esta actitud. Una era de carácter práctico: lo primero que precisaba el obrero era una educación integral y cultural básica de la que por lo general carecía: «El ochenta por ciento de los militantes confederales eran autodidactas» ${ }^{12}$. La segunda razón era ideológica y contextual. Formar profesional y técnicamente al obrero era formarle como trabajador especializado al servicio del patrón. Solo a partir de la segunda mitad de los años 20, y sobre todo durante la Segunda República y la Guerra Civil, se comenzarían a introducir en el programa educativo anarquista estas enseñanzas específicamente «obreras» ${ }^{13}$.

Gómez Casas, Juan: Historia del anarco sindicalismo español, Madrid, zYX, I968, p. I29.

8 Castiello, Chema: «Nota biográfica», en Memoria de Eleuterio Quintanilla, Gijón, Aula Popular José Luis García Rúa, 20I6, pp. 15-28 (p. 25).

9 Gómez Casas, Juan: Historia del anarco sindicalismo..., op. cit., p. I29.

10 Ibid., p. I3I.

" JaCAS, Gerard: «La escuela anarquista ayer. Entrevista a Federica Montseny», Cuadernos de Pedagogía, 28 (1977), pp. 65-68 (cita en pp. 66-67).

${ }_{12}$ Ibid., p. 66.

13 Cardona Ángeles y Cardona, Francisco L.: La utopía perdida, Barcelona, Bruguera, 1978, pp. 19I-200. Todas las generalizaciones tienen sus excepciones. Así, pueden encontrarse textos sobre la necesidad de una relación armónica, equilibrada, entre brazo y cerebro, entre lo manual y lo intelectual, en conocidos anarquistas como Mella, Ricardo: Cuestiones de enseñanza libertaria, Bilbao, zero zyX, 1979, pp. 9I-95 («El cerebro y el brazo», artículo publicado en I9I3 en el n. 8 de Acción Libertaria). 
Queda por considerar el ideario y prácticas educativas del anarquismo en la Guerra Civil en relación con los temas aquí tratados. En primer lugar, porque el principio antiestatista sería dejado a un lado con la participación del anarquismo en el Consejo de la Escuela Nueva Unificada (CENU), órgano regulador de la enseñanza en Cataluña, y en el Ministerio de Instrucción Pública, dirigido por Segundo Blanco desde abril de i938. Se trata de hechos conocidos y estudiados. Limitémonos a dejar constancia de la quiebra, en un contexto bélico excepcional, de uno de los principios básicos del anarquismo libertario. En segundo lugar, porque tras la configuración de sindicatos de enseñanza comarcales y regionales, en junio de 1937, pudo constituirse en Valencia la Federación Nacional de Sindicatos de Enseñanza de la CNT tal y como se había propuesto en el IV Congreso celebrado en Zaragoza en mayo de $1936^{14}$. En tercer lugar, porque, pese a la quiebra del principio antiestatista y a este proceso de centralización sindical, el movimiento educativo anarquista siguió mostrando durante el período bélico ese rasgo autónomo, de iniciativas «libres»"15, que siempre le había caracterizado, con especial énfasis en el campo de la formación profesional y técnica. Por último, porque la Guerra Civil puso en evidencia los problemas que planteaba llevar a la práctica, en un contexto de enfrentamiento bélico, el principio de no proselitismo y consecución, mediante la educación, de seres humanos intelectualmente libres de todo prejuicio político o religioso, así como de compaginar, teóricamente y en la práctica, la acción educativa en pro de un «comunismo libertario» con los principios escolanovistas de respeto al libre desenvolvimiento e intereses del niño al que en algunos momentos se sentían cercanos algunos maestros libertarios ${ }^{16}$. Una cuestión que, en otro contexto, volveremos a encontrar en el anarquismo de los años setenta.

\section{I.2. Socialismo}

En sus comienzos, el Partido Socialista, fundado en I879, comparte con el anarquismo la propuesta de crear una red cultural y educativa propia de índole asimismo laica, racionalista y científica. Los testimonios en tal sentido son abundantes. Tanto en cuanto a la desconfianza o rechazo de la escuela burguesa o

14 Martínez, Miguel Ángel: Propuestas educativas del movimiento libertario en Madrid, durante la Guerra Civil, Madrid, Fundación Salvador Seguí, 2016, pp. 37-50. Anteriormente, los enseñantes cenetistas se afiliaban al Sindicato de Profesionales y Técnicos o al de Oficios Varios de cada localidad.

${ }_{15}$ Las iniciativas partieron del grupo de Mujeres Libres, de las Juventudes Libertarias, de los Ateneos Libertarios, de las colectivizaciones llevadas a cabo y de los diversos sindicatos cenetistas. Para más detalles, véase Martínez, Miguel Ángel: Propuestas educativas..., op. cit., y Tiana FeRRER, Alejandro: Educación libertaria y revolución social (España 1936-1939), Madrid, UNED, 1987.

${ }_{16}$ Para más detalle, VIÑAO, Antonio: «Politics, education and pedagogy: ruptures, continuities and discontinuities (Spain, 1936-1939)", Paedagogica Historica, LI (IV) (2015), pp. 405-417. Versión española en «Política, educación y pedagogía: rupturas, continuidades y discontinuidades (España, 1936-1939)", Con-Ciencia Social, I9 (2015), pp. 15-24. 
capitalista ${ }^{17}$, como en relación con la necesidad de fundar «escuelas puramente socialistas, de donde salgan luchadores firmes, inteligentes y convencidos, de donde broten hombres del porvenir, libres, justos y buenos» ${ }^{18}$.

Consecuencia de esta posición sería la fundación, a partir de los primeros años del siglo xx, de las Casas del Pueblo como espacio de sociabilidad obrera en cuyo seno no solo se llevaban a cabo actividades sindicales y recreativo-culturales -biblioteca con prensa diaria y revistas, orfeón, conferencias, veladas poéticas y teatrales, lecturas públicas, cursos, excursiones-, sino que también funcionaban, con diversa fortuna, escuelas diurnas para el alumnado en edad escolar, nocturnas para adultos y técnico-profesionales.

No obstante, con independencia de lo anterior, y no sin oposición o conflictos con el sector obrerista y sindical del partido, en especial con la Unión General de Trabajadores (UGT) fundada en I888, en esos mismos años surge en el Partido Socialista, promovido por su sector intelectual y docente, una corriente de opinión que propugna cambios, entre reformistas y rupturistas, en el sistema educativo público y en la política educativa.

Las propuestas en relación con las transformaciones a introducir en el sistema educativo -es decir, el modelo de nuevo sistema educativo promovido desde el Partido Socialista- son asimismo conocidas. Aunque pueden hallarse demandas anteriores de mejoras concretas o generales de la educación pública, no sería hasta I9I8 cuando en el xI Congreso del Partido Socialista la Escuela Nueva -asociación o agrupación fundada en igıo por Manuel Núñez de Arenas en la Casa del Pueblo madrileña- presentara unas «Bases para un programa de instrucción pública», redactadas por Lorenzo Luzuriaga, que implicaban una transformación radical del sistema educativo vigente ${ }^{19}$. Un texto a considerar en el contexto más amplio de otros dos de intenciones y rasgos en buena parte similares, elaborados en la década de los años 20: el dictamen de la ponencia de enseñanza presentado por la socialista Asociación General de Maestros al xIv Congreso de la UGT en junio de 1920 , aprobado por unanimidad ${ }^{20}$ - y reiterado, como programa de dicha Asociación, en el primer número, de febrero de 1931, de la revista Trabajadores de la Enseñanza $a^{-21}$, y el «Programa de enseñanza» elaborado por Dionisio Correas

${ }^{17}$ «La instrucción del obrero, una instrucción científica y completa, que le haga ser hombre inteligente, útil a sí mismo y a sus semejantes, es imposible que pueda adquirirse en el sistema económico actual» (Prospecto de El Socialista, febrero de i886, en Iglesias, Pablo: Escritos I. Reformismo social y luch a de clases y otros escritos, Madrid, Editorial Ayuso, 1975, p. 79).

${ }_{18}$ Torralba Beci, Enrique: «Una escuela socialista», La Revista Socialista, Iv (82) (1906), p. 303.

19 No está de más recordar que Luzuriaga ingresaría en el Partido Socialista dos años más tarde, en 1920, y que el proyecto y actividades de la Escuela Nueva de Núñez de Arenas habían encontrado y encontrarían dificultades tanto en la UGT -en I9II se denegaría la solicitud de ingreso en el sindicato socialista de la Escuela Nueva-, como en el seno del mismo Partido Socialista. De hecho, Núñez de Arenas sería uno de los fundadores en 192I del Partido Comunista Obrero Español.

${ }_{20}$ El dictamen, firmado por Victoria Zárate, Juan Contreras, Lorenzo Luzuriaga y Andrés Ovejero, se inspiraba en las «Bases» de 19I8. Puede verse en DE Luis Martín, Francisco: Historia de la FETE (I909-1936), Madrid, FETE-Fondo Editorial de Enseñanza, 1997, pp. I09-III.

${ }_{21} \quad$ Ibid., pp. I26-I27. 
para el XII Congreso del Partido Socialista de $1928^{22}$. Aunque estos dos últimos textos constituyen formulaciones más concisas, y en ocasiones atemperadas, de las «Bases» de I9I8, a partir de estos tres documentos puede decirse que tanto el Partido Socialista como su organización sindical, la UGT, y el movimiento asociativo y sindical socialista del magisterio primario, contaban ya con un programa definido de transformación radical del sistema educativo basado, sustancialmente, en los principios de laicidad, gratuidad y coeducación; el deber y responsabilidad estatales de garantizar el derecho de todos a la educación; el modelo de escuela única o unificada para la población de seis a los catorce años con una formación profesional o técnica posterior hasta los dieciocho años -asimismo obligatoria para quienes no cursasen la segunda enseñanza-; el desarrollo y extensión de la educación infantil; la apertura de la universidad a la clase obrera; la introducción del trabajo manual con carácter obligatorio; la constitución de un cuerpo único docente, y la atención hacia las actividades e instituciones de cultura popular o extraescolares, entre otros aspectos.

Este paso en el programa de acción del Partido Socialista de una «educación obrera» a una «educación nacional» ${ }^{23}$ debe matizarse. No es extraño hallar propuestas de cambios sustanciales y demandas de mejora en la política y el sistema educativo entre quienes defendían la necesidad de disponer de una red escolar socialista, ni las propuestas en favor de un sistema educativo de nuevo cuño, de índole estatal o pública, se planteaban negando la necesidad asimismo de una red escolar propia, al menos con carácter remedial o sustitutorio de una educación pública deficiente. Lo que sucede es que las cuestiones a debatir no serían ya las propias de la puesta en funcionamiento de dicha red -destinatarios, profesores, locales, financiación, programas, métodos, inserción en las Casas del Pueblo, actividades extraescolares, etc. - , sino la naturaleza reformista o revolucionaria del nuevo sistema educativo que se proponía y las maneras, modos o vías para llevarlo a cabo. Entre ellos, por ejemplo, si la implantación de ese sistema educativo socialista exigía un previo proceso político revolucionario y el acceso del proletariado al poder, sin el cual todo intento era vano, o si, por el contrario, era posible promover dicho proceso mediante reformas sustanciales en el sistema educativo burgués.

No sería este el único dilema que se planteara a las nuevas asociaciones sindicales de docentes socialistas -la Asociación de Profesores Racionalistas (1909I9I2), después Asociación General de Maestros (I9I2-I9I4 y I9I9-I93I) y en I93I

22 Correas, Dionisio: «Programa de enseñanza», en Partido Socialista Obrero Español: Convocatoria y orden del día para el XII congreso ordinario del partido, Madrid, Gráfica El Socialista, 1927, pp. 450-454. Dionisio Correas, militante de la Agrupación Socialista Madrileña, desempeñó un importante papel en el movimiento asociativo y sindical socialista del magisterio como miembro relevante, primero de la Asociación de Profesores Racionalistas y después de la Asociación General del Magisterio y de la Federación de Trabajadores de la Enseñanza (FETE).

${ }_{23}$ Guereña, Jean-Louis: «La educación obrera en las Casas del Pueblo», en Redero, Manuel (coord.): Sindicalismo y movimientos sociales, Madrid, UGT-Centro de Estudios Históricos, 1994, pp. 5I-72 (p. 67). 
Federación de Trabajadores de la Enseñanza-24, como no lo sería después, tras el franquismo, o antes, después y ahora, en el seno del movimiento obrero en relación con la educación. Como quedó indicado, pueden señalarse otros dilemas. En este caso, sin embargo, nos centraremos en el que dividió al movimiento obrero, en especial al profesorado socialista, entre un sector reformista y otro revolucionario tanto en España, antes y durante la Guerra Civil, como fuera de ella.

El nuevo lema de la «conquista de la escuela pública» lanzado desde las páginas de El Socialista en $1914^{25}$ constituía, como se ha dicho, un cambio, reforzado en los años siguientes, en la estrategia seguida hasta el momento tanto por el Partido Socialista como por la UGT y las asociaciones de profesores integradas en este sindicato. Sean cuales sean las razones -el creciente peso en el partido y en el sindicato de intelectuales, profesores y miembros o personas afines a la Institución Libre de Enseñanza; la experiencia de la acción municipal de los primeros concejales socialistas y sus iniciativas y peticiones en materia de enseñanza; la insuficiencia y dificultades económicas de la red escolar propia-, el hecho es que dicho cambio provocaría la confrontación entre quienes consideraban que exigía previamente la toma del poder por la clase trabajadora, mediante un proceso revolucionario, y la de quienes estimaban que dicho proceso podía alcanzarse introduciendo reformas y transformaciones sustanciales en la política educativa. Analizar este dilema requiere considerar dos hechos clave: el papel desempeñado por la existencia de un modelo educativo de referencia, el soviético, y la posición de ambas opciones ante el movimiento pedagógico internacional de la Escuela Nueva.

Nada mejor para referirse al primer aspecto -y enlazar desde allí con el segundo- que la lectura de las actas de las Jornadas pedagógicas organizadas por la Internacional de los Trabajadores de la Enseñanza (ITE), celebradas en Leipzig en abril de 1928 con el título de Pedagogía proletaria ${ }^{26}$, con la asistencia de «500 delegados venidos de todo el Mundo» ${ }^{27}$.

Contextualicemos las Jornadas de Leipzig. La socialista Asociación General del Magisterio (AGM), antes mencionada, se había adherido en 1920 a la ITE, pese a que, como sindicato de la UGT, estaba integrada en la Federación Sindical Internacional,

24 La circular de i912 con la que la Asociación General de Maestros se presentaba ante el magisterio primario y el profesorado, pidiendo su afiliación a la misma, puede verse en LLOpis, Rodolfo: Hacia una escuela más humana, Madrid, Editorial España, 1934, pp. 98-100. Se halla inserta en un capítulo, en buena parte redactado durante la dictadura primorriverista, titulado «El sindicalismo en la enseñanza» (pp. 68-III), en el que se defiende la formación de sindicatos de maestros y el derecho a la huelga, y se expone la situación al respecto, como ejemplos a seguir, en Francia y Bélgica.

25 Electra: «De la escuela popular», El Socialista, I.714 (I de febrero de I9I4), pp. 2-3.

${ }_{26}$ Pedagogía proletaria. Informes, tesis y debates de las Jornadas pedagógicas de Leipzig organizadas por la Internacional de los Trabajadores de la Enseñanza. Pascuas de 1928, París, Ediciones de la Internacional de los Trabajadores de la Enseñanza, 1930. Una selección de los informes presentados en dichas Jornadas, no siempre completos ni traducidos del mismo modo -y con alguna atribución o autoría errónea-, se publicó, junto con otros textos de docentes o responsables del sistema educativo soviético, en La escuela y el niño proletario (la nueva pedagogía soviética), Valencia, Ediciones de la «Unión de escritores y artistas proletarios», s. a. (pero hacia 1937), traducciones y composición de Armando Bazán.

27 Llopis, Rodolfo: Hacia una escuela más humana, op. cit., p. I34. 
de ideología socialista, y no en la Internacional Sindical Roja, de ideología comunista. La ITE, sin embargo, estaba «dominada y dirigida por elementos comunistas ${ }^{28}$ a diferencia del Secretariado Profesional Internacional de la Enseñanza (SPIE), constituido en I926, al que se incorporarían las secciones nacionales de la ITE de Alemania, Holanda e Inglaterra y, tras las Jornadas en I928, la de Bélgica, descontentas con el predominio comunista en esta última. Un predominio no solo cuantitativo -desde I924 se había incorporado a la ITE la Federación de Maestros de la Unión Soviética con 600.000 miembros-, sino también organizativo y cualitativo ${ }^{29}$.

No está de más advertir que, por lo que a España respecta, el mismo año de las Jornadas de Leipzig, en 1928, tendría lugar el XII Congreso del Partido Socialista en cuya convocatoria, al referirse a la situación de los distintos partidos socialistas de otros países, se decía: a) que la Internacional Socialista contaba en la Rusia de los zares con tres partidos, todos ellos ilegales: los «maximalistas» o bolcheviques, los «socialistas demócratas» y los «socialistas revolucionarios»; b) que en «la revolución rusa» los bolcheviques se habían aprovechado «de lo que había sido el esfuerzo y sacrificio del pueblo ruso, orientado» por los otros dos partidos; y c) que la «revolución bolchevique» se había hecho contra estos mismos dos partidos socialistas declarándolos «ilegales».

En estas condiciones -se concluía-, no nos es fácil entrar a tratar lo que pasa en Rusia. Para censurar a los gobernantes rusos, no queremos hacerlo; para elogiarlos, nos falta documentación de origen fidedigno.

Los gobernantes del pueblo ruso han hecho un daño enorme al Socialismo y a la Democracia. La revolución rusa, perdurando, sabrá perdonárselo en su día, y con ella, la clase trabajadora ${ }^{30}$.

Es en este clima de enfrentamiento entre socialistas y comunistas en el que hay que situar las Jornadas de Leipzig. En ellas, el Gobierno alemán solo permitiría la entrada en el país de un miembro de la delegación rusa, A. P. Pinkievitch ${ }^{31}$ y los informes del resto (Epstein, Pistrakt, Chulguin y Chatzky) tuvieron que ser leídos «sin que sus autores pudiesen defenderlos y ampliarlos», según se expresó desde el Secretariado General de la ITE en el prólogo del libro ${ }^{32}$. No fue necesario

28 De Luis Martín, Francisco: Historia de la FETE (I909-I936), op. cit., p. I2O.

29 Sobre las internacionales del magisterio primario y sus convenciones y congresos durante el primer tercio del siglo xx, véase Llopis, Rodolfo: Hacia una escuela más humana, op. cit., pp. II2-I53.

3o Partido Socialista Obrero Español: Convocatoria y orden del dia..., op. cit., p. 675.

${ }^{31}$ Su obra más conocida en España, La nueva educación en la Rusia soviética, sería publicada por Aguilar en 193i. Sobre la difusión en España del modelo educativo soviético, véase FERNÁNDEZ SORIA, Juan Manuel: «Influencias nacionales europeas en la política educativa española», Historia de la Educación, 24 (2005), pp. 39-95 (pp. 83-87). Desde una perspectiva general, sobre la recepción y el impacto de la Revolución rusa en España, remitimos a los trabajos de Sebastiaan Faber, Ángel Duarte, Francisco Erice, José Luis Martín Ramos y Josep Puigsech Farràs incluidos en Andrade. Juan y Hernández SÁnchez, Fernando (eds.): IgI7. La Revolución rusa cien años después, Madrid, Akal, 20I7.

${ }_{32}$ Pedagogía proletaria..., op. cit., p. 5. Tampoco pudieron asistir los delegados franceses y polacos por negarles sus gobiernos los pasaportes. En todo caso, la ausencia de los delegados rusos 
que la delegación soviética se presentara en pleno. La lectura de las distintas intervenciones y debates de las Jornadas, así como la inclusión al final de ellas de la conferencia sobre «la escuela soviética» pronunciada en 1929 por Coignot en el Congreso de la Federación Unitaria de Francia, no deja lugar a dudas sobre las tesis que predominaron en Leipzig. En efecto, como por dicho Secretariado General se dijera en el prólogo:

El leit motiv de todos los informes [...] consiste en afirmar que el régimen capitalista no garantiza los intereses del niño proletario, quien no podrá desarrollarse normalmente sino después de que los trabajadores hayan conquistado el Poder y hayan establecido un régimen nuevo más equitativo, es decir, un régimen, socialista o comunista ${ }^{33}$.

$\mathrm{Y}$ aunque, intentando contentar a unos y otros, se afirmara seguidamente que ello no significaba que los «pedagogos socialistas» no tuvieran nada «que hacer en [un] régimen capitalista»-las intervenciones de Freinet o Bernfeld, entre otros, mostraban tal posibilidad-, el hecho es que aquellas intervenciones que ponían a la escuela y los educadores «al servicio de los niños» en función de su «curiosidad»; o el acento en la necesidad de «conocer y respetar la personalidad del niño», o en la labor, en este sentido, de las «escuelas nuevas o de ensayo» -como en el caso del delegado español, Rodolfo Llopis-34, o incluso aquellas, como la de Carl Roesser, defendiendo, pese a su declive, la experiencia de las «escuelas experimentales» o del «trabajo» en Alemania ${ }^{35}$ no fueron bien vistas por quienes, desde la URSs -que ese mismo año, en 1928, iniciaba el primero de sus planes quinquenales- o desde otros países, en especial Alemania, tenían clara la inutilidad de las reformas, transacciones o nuevos métodos pedagógicos ensayados en los países burgueses o capitalistas. Solo el acceso al poder de la clase proletaria y la implantación transitoria, siguiendo el modelo soviético, de la dictadura del proletariado harían posible el advenimiento de una auténtica

estuvo compensada con la relevancia del pabellón de la uRss en la Exposición escolar organizada con motivo de las Jornadas. En palabras de Rodolfo Llopis, «el interés de la Exposición se concentra en el pabellón ruso» y en la muestra y explicaciones que en él se hacían del modelo educativo soviético (Hacia una escuela más humana, op. cit., pp. 183-184).

33 Ibid., p. 7.

34 LLOPIS, Rodolfo: «Programas y métodos. En la escuela elemental», en Pedagogía proletaria..., op. cit., pp. 159-162. Su versión de lo acordado en Leipzig reconocía la existencia de divergencias, pero ofrecía una imagen distorsionada de lo allí sucedido pues, tras afirmar que existió «unanimidad al estimar que el problema de la educación no se resolverá radicalmente mientras no se produzca una honda transformación social», añadía que, hasta que llegara ese momento, "los maestros" tenían en sus manos todo un mundo de posibilidades de acción» (Llopis, Rodolfo: «Reseña de Pédagogie Proletarienne», El Sol, io de febrero de 1929; recogido en Совв, Christopher H.: La cultura y el pueblo. España, I930-1939, Barcelona, Laia, 1981, pp. 369-371). En Hacia una escuela más humana, op. cit., p. I35, reconocía, sin embargo, la diferencia sustancial entre los que pedían en dichas Jornadas «la implantación de la escuela de clase» y los que reclamaban «la realización de una escuela humana».

${ }^{35}$ Roesser, Carl: «La Escuela del Trabajo en Alemania», en Pedagogía proletaria..., op. cit., pp. $165-168$. 
educación y pedagogía proletarias. Ese era el camino emprendido por la URss y el ejemplo a seguir.

Las argumentaciones y manifestaciones en tal sentido fueron continuas. La escuela capitalista estaba al servicio de la clase dominante y no del proletariado por la simple razón de que la escuela era un producto del medio social, es decir, de las relaciones de clase y producción. Por tanto, «la escuela, como organismo, no puede llegar a ser progresista más que después del cambio de las relaciones de propiedad y de las relaciones sociales mediante la revolución proletaria» ${ }^{36}$. Es más, en la autorizada opinión de Pinkiévitch, aunque era cierto que «la enseñanza se ha organizado siempre para servir a las clases dominantes de la población» y que, por tanto, no existe país alguno con una «organización escolar capaz de dar satisfacción a toda la sociedad», que «responda a las exigencias de la humanidad» -algo solo posible «cuando desaparezcan las clases sociales, es decir, en un régimen comunista»-, también lo era que tales condiciones no se daban ni siquiera en «una sociedad de transición creada por la dictadura del proletariado»37. Una dictadura que solo era «una etapa necesaria para la instauración del comunismo, y

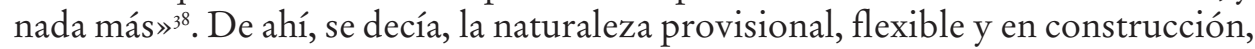
tanto de la sociedad como del sistema educativo soviético, con sus deficiencias -sobre todo, por la herencia recibida-, problemas, insuficiencias e incluso contradicciones, reconocidas por la casi totalidad de las intervenciones de los informes de los delegados de la URSS $^{39}$. Un carácter compatible con su índole excepcional, desconocido y sin precedentes en la historia de la humanidad. Se trataba, en definitiva, de un «mundo nuevo»: el del país, el único país, que estaba «construyendo el socialismo». Por ello, no solo debía ser resguardado de todo ataque o crítica por parte de los «países imperialistas»-como bajo el grito de «No toquéis a la Unión Soviética» demandaba en 1929 Coignot al finalizar su conferencia en el Congreso de la Federación de la Enseñanza unitaria de Francia- ${ }^{40}$, sino que, además, por constituir un faro que iluminaba el camino a seguir por otros países, había que demostrar su fortaleza y adecuación a las nuevas ideas pedagógicas frente a la debilidad, ineficacia y decadencia de las instituciones y movimientos de ensayo y reforma que, bajo el paraguas semántico de «Escuela Nueva», eran el p. 106.

${ }^{6}$ Hierl, Ernst: «Fin de la educación. Escuela y religión», en Pedagogía proletaria..., op. cit.,

${ }_{37}$ Pinkiévitch, A. S.: «La organización del sistema escolar. Organización de la enseñanza en la U.R.s.s.», en Pedagogía proletaria..., op. cit., p. I43.

${ }_{38}$ Chulguin: «Fin de la educación. Escuela y Estado», en Pedagogía proletaria..., op. cit., p. 9I.

39 El tono o acento en el carácter provisional o en construcción del sistema educativo soviético, perceptible en las intervenciones de los delegados de la URss en las Jornadas de i928 contrastan con el más asentado y seguro de sí mismo, menos crítico, de los textos de los dirigentes de la educación soviética (Svadrovski, Gaissinovitch, Glatman, Dachinchevski, Klaleunovski) incluidos en I937 en La escuela y el niño proletario (la nueva pedagogía soviética). Todos ellos habían sido escritos tras la finalización del primer plan quinquenal de I928-I932, en plena ejecución del segundo (I933-I937) y en un contexto internacional de ascenso del nazismo y el fascismo: la «contundencia» era, en esa situación, obligada.

40 Cogniot: «La escuela soviética», en Pedagogía proletaria..., op. cit. 
origen de un peligro no menos dañino: la creencia ilusoria en una educación a la vez socialista y progresiva en las sociedades capitalistas.

Las diatribas y críticas contra el escolanovismo abundan por doquier, y no solo en los informes de los delegados soviéticos. Chulguin, por ejemplo, dedicaba una parte de su intervención al «bluff de la escuela única y de la escuela renovada», a las llamadas «escuelas nuevas» cuyo fin, en definitiva, no era otro que formar una «minoría selecta» de «directores» entre «los hijos de la burguesía» ${ }^{4}$. Pistrak, por su parte, distinguía en las «escuelas experimentales» fundadas en los países capitalistas por «intelectuales que pretenden sustraerse a la influencia de la burguesía» tres «maneras de desenvolverse»:

O degeneran en escuelas privilegiadas para la clase poseedora, o restringen sus ensayos pedagógicos dentro de los límites permitidos por la sociedad burguesa, o se ponen en contradicción con las relaciones sociales establecidas, y, entonces, peligra su existencia ${ }^{42}$.

Su juicio sería confirmado por los informes presentados sobre el fracaso de las reformas escolares planteadas en diversas ciudades o estados alemanes, tras los sucesos revolucionarios de 1918, con el fin de implantar una escuela única y laica, basada en trabajo ${ }^{43}$, o de desarrollar la idea de «comunidad escolar» en Alemania o Viena ${ }^{44}$. No mejor suerte corrían el «self-goverment», el principio de neutralidad, el método de proyectos o la cuestión de la disciplina escolar, entre otros temas, en los países capitalistas. Sin el previo acceso al poder de la clase proletaria, se trataba de ideas, métodos o formas de enseñanza quizás meritorias, y de las cuales algo podía aprenderse, pero abocadas al fracaso o, en el peor de los casos, a sostener y renovar, solo en apariencia, la sociedad de clases y el dominio de la burguesía.

En definitiva, «las exigencias del Estado proletario respecto a la escuela» correspondían «de la manera más exacta, más frecuente, al desarrollo del niño» ${ }^{45}$. Allí donde no existiera un Estado de ese tipo, los maestros, junto con los «padres proletarios», debían reivindicar «la autonomía interior de la escuela», la libertad organizativa y metodológica para dar una «orientación social a los escolares» recrudeciendo así «la lucha social por la transformación del sistema existente» y desarrollando los gérmenes de una educación social proletaria» ${ }^{46}$.

${ }_{41}$ Chulguin: «Fin de la educación. Escuela y Estado», en Pedagogía proletaria..., op. cit., pp. $85-88$.

42 Pistrak: «Fin de la educación. Escuela y sociedad», «Fin de la educación. Escuela y Estado», en Pedagogía proletaria..., op. cit., pp. 81 y 74-75.

43 Hommes, Edith: «La organización del sistema escolar. La organización de la enseñanza alemana», y Rossger, Karl: «Programas y métodos. La escuela del trabajo en Alemania», en Pedagogía proletaria..., op. cit., pp. I27-I43 y I65-168 respectivamente.

44 Bernfeld, Sigfried: «Disciplina escolar. La comunidad escolar», en Pedagogía proletaria..., op. cit., pp. I84-I94.

45 Chulguin: «Fin de la educación. Escuela y Estado», en Pedagogía proletaria..., op. cit., p. 9I.

${ }_{46}$ Pistrak: «Fin de la educación. Escuela y sociedad», en Pedagogía proletaria..., op. cit., pp. 80 y 83 . 
Por lo que respecta a España,

a partir de 1934, y como consecuencia sobre todo de la radicalización del sector socialista liderado por Largo Caballero y del nuevo papel cultural jugado por las Juventudes Socialistas, se intentará formular un nuevo proyecto pretendidamente revolucionario en el que la influencia de las realizaciones soviéticas y el deseo de continuar o heredar el primer proyecto cultural socialista -al menos en su caracterización como proyecto de clase- constituyen sus notas más relevantes ${ }^{47}$.

Esta orientación general se vio reforzada en el ámbito de la educación formal por la progresiva asunción por la AGM primero, y después por la FETE -O de algunas de sus agrupaciones regionales como la asturiana y la gallega-, de las tesis revolucionarias sostenidas en 1928 en las Jornadas de Leipzig, así como por la creciente difusión de informaciones relativas a las realizaciones del sistema educativo soviético y el descontento de aquella parte del profesorado que estimaba insuficientes las reformas adoptadas durante el primer bienio republicano. Las medidas contrarreformistas introducidas por la derecha tras su triunfo en las elecciones de 1933 vinieron a reforzar todavía más la creencia de que solo un proceso revolucionario podía abrir la puerta a una transformación radical de la educación en España ${ }^{48}$. Algunas de las tesis mantenidas, por ejemplo, en el I Congreso de la AGM, celebrado en los primeros días de abril de I93I, calcaban, palabra por palabra, expresiones o frases escuchadas tres años antes en Leipzig.

Esta posición se afianzaría en el Congreso Extraordinario de la FETE celebrado el 5 de abril de 1934, con el acceso a la dirección del sindicato del sector revolucionario liderado por César García Lombardía, quien tres años después, durante la Guerra Civil, será nombrado director general de Primera Enseñanza en el ministerio del comunista Jesús Hernández. Ese mismo día tendría lugar una manifestación de maestros en el patio del Ministerio del Instrucción Pública. Era «la primera vez que los maestros utilizaban ese medio» como acción en defensa de sus reivindicaciones. Ante «la negativa del ministro a hablar con todos y solicitar hacerlo con una comisión se oyeron gritos de protesta y algunos maestros pretendieron subir violentamente» -había una numerosa «presencia» de policías y guardias de seguridad- «al primer piso». De inmediato, la policía desalojó a los manifestantes y detuvo a siete de ellos, entre los que, junto a otros maestros de la FETE, se hallaba García Lombardía. Este hecho, muestra de una actitud más combativa, contribuyó a incrementar su «prestigio» en la FETE y entre el magisterio primario ${ }^{49}$. Para buena parte de ese sector revolucionario el «modelo» a seguir era el soviético:

47 De Luis Martín, Francisco: «Sinopsis de un proyecto de investigación sobre la cultura obrera socialista en España», Con-Ciencia Social, I4 (20IO), pp. I27-I37 (pp. I27-I28).

${ }^{48}$ De Luis Martín, Francisco: Historia de la FETE (I909-1936), op. cit., pp. I29-I35.

49 Ibid., pp. 172-173. El movimiento internacional abocaba a ello: solo dos meses antes, en febrero de 1934, los sindicatos de maestros franceses (el Sindicato Nacional de Maestros y la Federación General de Enseñanza) habían transgredido la solidaridad «acordada» con las organizaciones de trabajadores (la CGT) no limitándose, como se les pedía, a ejercer «la más bella y eficaz solidaridad» que, ante una huelga, podían desplegar con los trabajadores manuales, esto es, «continuar en sus clases, educando 
Los trabajos, los ensayos y artículos sobre la uRss y sobre la organización educativa implantada en sus territorios se harán muy frecuentes en las páginas del boletín sindical [Trabajadores de la Enseñanza]. Más adelante, la FETE organizará incluso un viaje de estudios a ese país y diversos militantes acudirán allí para estudiar in situ las realizaciones e iniciativas puestas en práctica por el comunismo ruso. Del mismo modo, los planteamientos pedagógicos y organizativos de la ITE, basados en la Escuela Única del Trabajo, volverán a ocupar un lugar central como fuente de inspiración y programa de trabajo. El ejemplo ruso y la doctrina de la ITE conducían al mismo punto, a la necesidad de la revolución social como paso previo a la revolución educativa ${ }^{50}$.

\section{Los años de plomo (1936-1939)}

La oportunidad para llevar a cabo desde el gobierno estatal o regional los programas educativos del socialismo revolucionario y del anarquismo (y, con el mismo empeño, potentes actividades de educación no formal) surgiría como reacción al golpe de Estado del I7-I8 de julio de 1936, y con la consiguiente revolución social y política que se produjo, como reacción, en el bando republicano.

El acceso al poder público durante la Guerra Civil de la UGT y CNT y de los sindicatos del profesorado integrados en ellas es un hecho conocido y estudiado, sea en el Ministerio de Instrucción Pública y Bellas Artes (dirigido por el comunista Jesús Hernández, con el apoyo y colaboración de la FETE, y posteriormente por el anarquista Segundo Blanco), sea, en una labor conjunta de ambos sindicatos, en el CENu de la Generalidad de Cataluña. Puede considerarse, pues, a las dos organizaciones sindicales responsables en buena parte de la política educativa republicana durante la Guerra Civil, salvo el inicial y breve ministerio del «institucionista» Francisco Barnés.

Lo que nos interesa constatar sobre esta cuestión es que:

- Cuando las circunstancias políticas les permitieron el acceso al poder, ambas organizaciones, incluida la tan remisa CNT a participar en la política institucional y siempre celosa de su independencia frente al poder público, intentaron, desde el mismo, llevar a la práctica sus ideas en relación con la educación. Que dichas circunstancias -la Guerra Civil con las consiguientes dificultades para mantener abiertas las escuelas y centros docentes; la carencia de un profesorado acorde con dichas ideas ${ }^{\text {II }}$; la supeditación del

a los hijos de los huelguistas». Por el contrario, ante el avance de la reacción fascista, convocan una huelga general de veinticuatro horas el día 24 de febrero de 1934 que será seguida por el $80 \%$ de los maestros nacionales. Era la primera vez que se producía un hecho de esa naturaleza (LLopis, Rodolfo: Hacia una escuela más bumana, op. cit., p. 74).

so Ibid., pp. I7I-I72.

st La no identificación de buena parte del profesorado -y de los funcionarios del ministerio responsable de la educación- con la Revolución rusa fue una de las dificultades a las que tuvieron que hacer frente sus promotores. En palabras de un destacado miembro del Comisariado de Instrucción Pública, «pocos fueron los maestros que desde el primer momento ofrecieron su trabajo y su vida 
sistema educativo al objetivo prioritario de la derrota del fascismo; la evolución de los acontecimientos bélicos, etc.- dificultaran esos intentos no cuestiona los hechos.

- Ambas organizaciones y sindicatos eran conscientes de que la revolución popular que había tenido lugar como reacción al golpe de Estado era la que posibilitaba ir más allá de las reformas del primer bienio republicano. Tal y como se decía en el preámbulo del Proyecto de enseñanza de la Escuela Nueva Unificada de la Generalidad de Cataluña, de 1936, eran el «momento revolucionario» que se vivía y «las fuerzas libertadoras de la hora presente» los que permitían aspirar a la consecución de «los ideales de ayer» traduciendo «en normas y preceptos los nuevos anhelos de saber y de cultura de la clase proletaria», y llevando de este modo a su pleno desarrollo lo dispuesto en materia de educación en la Constitución de i93r y en el Estatuto de Cataluña. Ahora, por fin, «este instrumento de dominio, que es la inteligencia, dejará de ser patrimonio de las personas ricas y recibirá en manos de los trabajadores y de los pobres aquella savia nueva que da el impulso de una naturaleza que todavía no ha estado maleada por el lujo y la molicie»s2.

Pese a todas las dificultades y circunstancias pueden señalarse afinidades entre la política republicana durante la Guerra Civil y la soviética. En palabras de Fernández Soria, «la República de I936, además de conceptos y propósitos, toma de Rusia algunas experiencias educativas y culturales más concretas» ${ }^{53}$. Como ejemplos menciona los institutos obreros; las «instrucciones» que García de Lombardía envía en noviembre de 1937 a los inspectores-jefes de enseñanza primaria para aplicar el plan de estudios aprobado unos días antes ${ }^{54}$; la organización de la

a la nueva causa revolucionaria» (EPSTEIN, M.: «La edificación cultural en la Unión soviética», en La escuela y el niño proletario..., op. cit., pp. 59-76 [p. 73]). En el caso español, es sabido que, para una plantilla de 50.000 maestros, la FETE contaba con unos 3.500 afiliados -no todos pertenecientes al magisterio primario, aunque estos fueran una clara mayoría- y que, durante la Guerra Civil, dicha cifra osciló entre los 30.000 y los 40.000 frente a los 22.000 del Sindicato Único de la Enseñanza de la CNT, pero hay que tener en cuenta no solo la obligatoriedad de la afiliación sindical, sino también la naturaleza como salvoconducto personal del carnet de afiliado a uno de los dos sindicatos permitidos. Por otra parte, no está de más indicar que la Asociación Nacional del Magisterio Primario, de índole no sindical, sino profesional, se vio forzada a integrarse en la FETE, lo que no resolvía las diferencias ideológicas existentes. Sobre el particular y la evolución del asociacionismo docente en España, véase De Luis Martín, Francisco: La FETE en la Guerra Civil española (1936-1939), Barcelona, Ariel, 2002, pp. 4I-6o, y Terrón, Aida: «El movimiento asociacionista del magisterio nacional. Orígenes y configuración histórica», Historia de la Educación, 6 (1987), pp. 279-299; "Cien años de defensa colectiva: la dinámica societaria y sindical del magisterio español», Sarmiento, 3 (I999), pp. I57-I82, y «Coordenadas del asociacionismo profesional de los docentes. Estado de la cuestión en España», Historia y Memoria de la Educación, I (2015), pp. 93-I30 (pp. I04-II8).

52 Generalidad de Cataluña. Consejo de la Escuela Nueva Unificada: Proyecto de enseñanza de la Escuela Nueva Unificada, Barcelona, Imprenta la Polígrafa, 1936, pp. 5-7.

${ }_{33}$ Fernández Soria, Juan M.: «Influencias nacionales europeas en la política educativa española», Historia de la Educación, 24 (2005), pp. 39-95 (p. 86).

54 Ministerio de Instrucción Pública y Sanidad: Plan de estudios de la escuela primaria, Barcelona, Talleres gráficos A. Núñez, 1937. 
juventud republicana en cuanto a su encuadramiento, objetivos y prácticas, y los contenidos de la propaganda escrita y cartelística. Asimismo, en los planes de estudio o propuestas pedagógicas elaboradas en el bando republicano resuenan los ecos de expresiones e ideas propias o cercanas a las mantenidas por la escuela soviética o las escuelas racionalistas de inspiración anarquista, mejor o peor combinadas con otras de procedencia escolanovistass.

Pero hay otro ejemplo no menos relevante: el que, pese a la ambigüedad y sincretismo de algunos textos, se quebrara el principio de neutralidad que, al menos en teoría, se había mantenido durante las reformas del primer bienio republicano. En 1933, Rodolfo Llopis, al dar cuenta de su labor como director general de Enseñanza Primaria desde abril de 1931, había dejado bien claras las diferencias entre la Revolución rusa y la española en un libro dedicado, por cierto, a la UGT. La primera, decía, «era obra de una clase social. O más bien de un partido político». La segunda no era «obra de un partido político ni de una clase social». Era «el producto de la inteligencia a la que llegaron diversos sectores políticos que coincidieron en lo que había que destruir y en lo que había que construir». Por eso, entre otros aspectos, frente al «grito de Zinovief» de que « $i$ Cueste lo que cueste, hay que apoderarse del alma de los niños!», con «la misma energía» y «resolución» la revolución española decía «iCueste lo que cueste, hay que respetar la conciencia de los niños! ${ }^{56}$. Tras julio de 1936 se oirán, desde luego, voces que aludan al libre desarrollo de la personalidad infantil, $u$ otras expresiones similares, pero el objetivo militar y la lucha contra el fascismo hacían insostenible ese principio de neutralidad que ya vimos tan denostado por quienes, en las Jornadas de la ITE de Leipzig en 1928, se inclinaban por el modelo escolar soviético como único posible frente al de las sociedades capitalistas y, en especial, a los propuestos por el movimiento de la Escuela Nueva.

\section{El «resurgir» del movimiento obrero (1950-1977): su función como referente}

Desde mediados de los cincuenta hasta entrados los sesenta se asiste en España a los primeros conatos de organización de un movimiento obrero que, si bien revela conexiones con su pasado -y en este sentido hablamos de un «resurgir»-57, necesitará buscar y operar con fórmulas reivindicativas y organizativas nuevas y particulares. El expolio político, cultural, económico y social a que fueron sometidos la clase obrera y sus sindicatos y centros educativo-culturales tras la Guerra Civil, junto con el fusilamiento, exilio o cárcel de buena parte de sus dirigentes y afiliados, explica que, aun cuando los trabajadores de los años cincuenta pudieran encontrar una tradición organizativa y de lucha a la que agarrarse, de la que tomar el testigo, sea por memoria colectiva, por lazos familiares o por sociabilidad laboral

" Para más detalle, véase VIÑAo, Antonio: «Politics, education and pedagogy...», op. cit.

56 Llopis, Rodolfo: La revolución en la escuela, Madrid, M. Aguilar editor, I933, pp. II-I2.

57 Término que tomamos del título del libro de SARTORIus, Nicolás: El resurgir del movimiento obrero, Barcelona, Laia, 1975 . 
-los saberes prácticos de resistencia y lucha que transmiten los viejos líderes «en el tajo»-, lo cierto es que las ideologías y las organizaciones obreras que las habían sustentado en el pasado parecían haber periclitado. Más centrados ahora en las reivindicaciones salariales y menos en el reparto del trabajo, las antiguas culturas obreras (la socialista, «dormida», y la anarquista, «interrumpida») ) $^{58}$ darán paso a otras, nuevas y potentes -la comunista y la obrero cristiana- que compartirán dinámicas de conflictividad en un tiempo y un espacio común a ambas.

El despegue económico español guarda estrecha relación con la emergencia de este movimiento obrero y las formas que va progresivamente adoptando. Grosso modo hablaríamos, entre 1950 y 1960, de una primera «fase espontánea» de lucha obrera, débil y muy localizada, que transitaría hacia una modalidad más intervenida - «espontaneidad provocada»: huelgas de 1962- para afirmarse como «movimiento organizado» desde 1967, hasta concluir, en 1977, con la «organización sindical»s. Se atribuye al «desarrollismo» mayor o menor peso en la conformación de ese nuevo movimiento obrero, lo cierto es que se basó en el desplazamiento de seis millones de trabajadores del sector primario. Emigrados cuatro millones de ellos hacia las concentraciones urbanas del país (Cataluña, País Vasco, Madrid, País Valenciano, Baleares) y cerca de dos millones más al extranjero, esa masa constituiría un enorme mercado de trabajo «disponible» para el crecimiento industrial. La España interior se quedó «vacía» ${ }^{60}$ de una mano de obra que se aglomeraba ahora en los suburbios de las grandes ciudades, sin que el Estado, las instituciones o las empresas realizaran planes de formación y acogimiento a unos trabajadores para los que la cualificación profesional resultaba innecesaria: los beneficios de la industria se sustentaban no en el factor tecnológico, sino en la intensividad del trabajo y en la explotación de una mano de obra inagotable, portátil, barata y disciplinada, garantizada por la fuerza coactiva de un contexto autoritario que reglamentaba las relaciones laborales férreamente, asegurando así la rentabilidad empresarial (es sintomático que la Ley de Convenios y la Ley de Orden Público coincidieran en el tiempo con el Plan de Estabilización de 1959). Este modelo supliría las carencias tecnológicas del desarrollismo español, haciendo innecesaria la implementación de un sistema de educación de masas propio de los países industrializados. Las «necesidades» educativas quedaron perfectamente cubiertas por un sistema clasista y tradicional que sobrevivió a este huracán sociológico, y que solo sería desbordado una década después por requerimientos políticos de carácter básicamente internacional.

Los modelos de conflictividad y de organización obrera responderán a la dinámica descrita. Sus primeras manifestaciones aparecen, de manera aislada, ya en los años cincuenta en el País Vasco, Madrid y Cataluña -hay también conflictos estudiantiles que los «acompañan», especialmente el de febrero de 1956- para eclosionar en 1957 con las fortísimas huelgas de la minería asturiana, que se extienden

58 Domènech Sampere, Xavier: Cambio politico y movimiento obrero bajo el franquismo. Lucha de clases, dictadura y democracia (1939-1977), Barcelona, Icaria, 2011.

59 SARTORIUS, Nicolás: El resurgir del movimiento obrero, op. cit.

6o Molino, Sergio: La España vacía. Viaje por un país que nunca fue, Madrid, Turner, 2016. 
a los sectores industriales de Madrid, Cataluña, Vizcaya, Valencia, e incluso a los trabajadores del campo. Se trataría de una primera fase de conflictividad «espontánea» que aporta ya los gérmenes de las nuevas formas organizativas que han de cristalizar en la década siguiente. Las «comisiones de obreros» surgen en este ciclo huelguístico como «delegados» de los trabajadores en huelga que negocian directamente con los patronos, al margen del Sindicato Vertical oficial, y se disuelven tras el fin del conflicto. Hasta ese momento las reclamaciones se sometían a los cauces legales: recogida de firmas, entrevistas con la dirección de la empresa, con el Sindicato Vertical, etc. A partir de ahora, mostrada la eficacia de las formas adoptadas, a pesar del ciclo represivo que sobrevino a continuación, la doble estrategia de formación de comisiones de obreros, abiertas a trabajadores «de todas las ideologías, creencias y afiliaciones» bajo el principio de unidad ${ }^{61}, \mathrm{y}$ el «entrismo» en el Sindicato Vertical, que practican tanto las Juventudes Obreras Católicas (JOc) y la Hermandad Obrera de Acción Católica (HOAC) como los comunistas, presentando a sus propios militantes para su elección como enlaces sindicales, se consolidará como forma de conflictividad y gestión de las huelgas y negociaciones colectivas. Además, «la negativa oficial a reconocer el derecho de huelga, de manifestación, de reunión y de libertad sindical condujo a que estos derechos apareciesen cada vez con más frecuencia como parte de las reivindicaciones obreras $»^{62}$. Estas serán también las formas que, una década después, comience a practicar, en muy pequeña escala todavía, el profesorado de la enseñanza privada que, a diferencia del profesorado del sector público, estaba obligado a afiliarse al sindicalismo vertical estatal.

$\mathrm{El}$ «conflicto por oleada» que se ensaya en este ciclo huelguístico parece un modelo de protesta exitoso para conquistar mejores condiciones laborales (pese a las detenciones, encarcelamientos, despidos, sanciones, listas de obreros «indeseables», estados de excepción, etc.). Volverá a aplicarse en las huelgas de 1962, la más extensa e intensa de las iniciadas desde 1956, con el epicentro en la minería asturiana pero inmediatamente extendida a las empresas del conjunto de la región y expandida a veintiocho provincias, con especial intensidad en Euzkadi, Cataluña y Madrid. Si hasta ese momento las comisiones de obreros habían limitado su ámbito de actuación a un pozo o una fábrica para disolverse después, a partir de ahora buscarán actuar como cauce de representación unitaria, con participación de una amalgama de organizaciones clandestinas en las que militantes comunistas

6r O’Malley, Paloma: La educación en la España de Franco, Madrid, Gens, 20Io, p. I88. Nicolás SARTORIUS consideraba un valor propio de este inicial movimiento obrero esta flexibilidad y apertura, frente a la indeseable rigidez orgánica característica de toda organización. En esas primeras comisiones de obreros, dice, se «está acostumbrado a no sentirse "miembro" de una organización a secas; antes bien, se considera un "elegido", un "participante", un representante o delegado de un determinado grupo de trabajadores». Se «sabe muy bien que en Comisiones no se "entra" o se "sale", sino que se es o no elegido, se participa o no en las asambleas, etcétera». No es una "organización más», sino un «movimiento organizado» [«Dialéctica de la unidad en el movimiento sindical», Zona Abierta, 7 (1976), pp. 15-32 (p. 26)].

62 De Riquer, Borja: La dictadura de Franco, Barcelona/Madrid, Crítica/Marcial Pons, 2oro, p. 549 . 
y cristianos, pertenecientes al Partido Comunista de España (PCE), la Unión Sindical Obrera (USO), la Juventud Obrera Católica (JOC), la Hermandad Obrera de Acción Católica (HOAC) y el Frente por la Liberación de los Pueblos de España (FELIPE), llevarán la iniciativa ${ }^{63}$.

Como señala Rubén Vega analizando esta fase de huelgas, particularmente las de la minería asturiana -insertas ya en la dinámica de «espontaneidad provocada»-, sería precisamente la represión subsiguiente la que «habrá de convertirse en un factor que proporcione cierta continuidad a las formas organizativas ya existentes -las comisiones de obreros- y dé lugar a la aparición de las primeras estructuras estables del movimiento». La recogida de fondos en los centros de trabajo para auxiliar a presos, deportados y despedidos, y las gestiones emprendidas en su apoyo y defensa "ofrecen una base para la actividad de las comisiones fuera de los momentos del conflicto». Funcionan como un elemento de articulación del movimiento y de estabilización importante ${ }^{64}$. Es, además, el momento en que el PCE renuncia a su «brazo sindical» (oso: Oposición Sindical Obrera) y apuesta por la organización de una coordinadora de las comisiones existentes en las diversas regiones españolas, intentado articularlas a escala nacional. A partir del año I963 las ya Comisiones Obreras, que comienzan a organizarse a nivel de rama y provincial, actúan con «la voluntad de organizar y coordinar a los trabajadores de las diferentes tipologías de empresa, independientemente de su procedencia ideológica y de si ocupaban o no un cargo de enlace sindical» ${ }^{65}$.

El franquismo necesitará reconocer la fuerza de las comisiones de obreros para lograr la paz en las empresas más combativas. A su vez, la movilización de otros sectores sociales (estudiantes, intelectuales, sacerdotes, fuerzas de oposición reunidas en Múnich en 1962); la mirada crítica que sobre la represión del movimiento huelguístico y la falta de libertades sindicales hace la comunidad internacional; y la posición de una Iglesia católica cuyo cardenal primado llegará a suscribir la carta de la HOAC y la JOC sobre los conflictos, reclamando el aumento salarial, la libertad sindical y el derecho a la huelga, vendrán en apoyo de una apertura del régimen que, «firmada la paz» en 1964, intenta medidas para ganar aceptación social y atraerse a los trabajadores. Una «estrategia de integración», diría José María Maravall, dirigida a «obstaculizar una creciente fuerza del movimiento obrero» ${ }^{66}$. La Ley de Asociaciones (1964), la Ley de Prensa (1966), la Ley Orgánica del Estado (1966) y la Ley Sindical de I6 de febrero de I97I son pasos en esa dirección, sin que por ello cese la conflictividad.

${ }_{3}$ Unión Sindical Obrera (USO): sindicato fundado en 1960 por jóvenes trabajadores cristianos de la HOAC y la Joc en Guipúzcoa. Hermandad Obrera de Acción Católica (HOAC): fundada en 1946. Desempeñó un papel relevante en la reconstrucción del movimiento obrero español y en la formación de las primeras comisiones obreras.

${ }_{64}$ Vega, Rubén: CC. OO. de Asturias en la Transición y en la Democracia, Oviedo, UR de Cc. oo. de Asturias, 1995, p. 3I.

65 Domènech Sampere, Xavier: Cambio político..., op. cit., p. 99.

${ }_{66}$ Citado por Martín De la Guardia, Ricardo Manuel: «La Organización Sindical española ante la ley Sindical de febrero de i971: tácticas propagandísticas en la conformación de un estado de opinión», https://dialnet.unirioja.es/descarga/articulo/66324.pdf. 
Los años siguientes refuerzan la organización de un «nuevo» movimiento obrero que pivota sobre las comisiones obreras, las cuales, frente a las tesis de organizaciones sindicales históricas partidarias de la abstención, se lanzan a «ocupar» el sindicalismo vertical presentando «sus» candidaturas a las elecciones a enlaces sindicales, cuyo éxito introducirá cambios importantes en la dinámica seguida hasta entonces al legitimar su papel interlocutor, su normalización y la presencia pública del movimiento:

Las elecciones sindicales de 1966 son un éxito para los trabajadores. Se alcanza una participación del 83,6\% del censo electoral y de los 206.296 enlaces elegidos, solo 46.433 son reelegidos y más de 50.000 están comprendidos entre los 2I y 30 años de edad. Se produce, pues, una amplia renovación y la juventud entra en tromba en los puestos de responsabilidad del movimiento obrero. El éxito de las elecciones supone un paso adelante en la legalización del nuevo movimiento obrero; la posibilidad de actuar abiertamente, de fundirse con las amplias masas, de poder plantear la lucha económica y política a un nivel completamente nuevo ${ }^{67}$.

El logro alcanzado «aceleró el proceso de creación de coordinadoras locales, comarcales y provinciales y de ramo, y el 9 de octubre de 1966 tuvo lugar la primera reunión de la coordinadora estatal de Comisiones Obreras» ${ }^{68}$. Esta reunión fundacional estuvo precedida, en 1965, de un manifiesto "Ante el futuro del sindicalismo» presentado por primera vez -fuera de las asambleas de trabajadores y los centros de trabajo- en diciembre de dicho año en el Club de Amigos de la UNEsco de Madrid. Los datos sobre la conflictividad laboral en esa década muestran la existencia de un antes y un después de esta consolidación sindical: si en 1962 el $87 \%$ de los conflictos respondían a razones estrictamente económicas y solo un II \% a protestas por solidaridad o por despido de algún compañero, en I967 predominarán las motivaciones políticas, indisociables ya de las anteriores: frente a un $13 \%$ de huelgas por mejoras salariales, las organizadas por razones solidarias, esencialmente detenciones y despidos, eran ya el $31 \%$ del total ${ }^{69}$.

No debe olvidarse, sin embargo -para explicar los ciclos de la conflictividad obrera en los años siguientes: huelgas de 1967-68, llegando a una auténtica explosión en los primeros años setenta-, que, como recuerda Sartorius, las conquistas eran frágiles e insuficientes y que las continuas subidas de los precios limitaban inmediatamente su alcance: seguía siendo imprescindible recurrir a las horas extraordinarias para poder vivir, los puestos decisivos del Sindicato Vertical siguen siendo elegidos a dedo y el derecho de huelga y el de reunión no estaban reconocidos. Romper esos techos constituye el objetivo -cada vez más unitario- de «la clase» ${ }^{70}$,

${ }_{67}$ SARTORIUs, Nicolás: El resurgir del movimiento obrero, op. cit., p. 46.

68 De Riquer, Borja: La dictadura de Franco, op. cit., p. 555 .

69 Gómez, Antonio: Tantas vidas, tantas luchas. Club de Amigos de la UNESCO de Madrid, I96I200I, Madrid, Club de Amigos de la Unesco, 2012, p. I20 (los datos se toman de un estudio de José M. ${ }^{a}$ Maravall que no se menciona).

$7^{\circ}$ Frente al sindicalismo vertical oficial donde se integraban, en un mismo sindicato, los trabajadores y empresarios de un sector determinado, un «sindicato de la enseñanza de clase» sería, 
que avanza en la coordinación organizativa, objetivos y formas de lucha. Asambleas de trabajadores, frecuentemente en iglesias, marchas desde las puertas de las fábricas, boicot a los transportes, etc., son acciones a escala nacional, contestadas con detenciones, juicios por asociación ilícita, manifestación y reunión ilegales, así como estados de excepción (enero de 1969 y otros ya en los setenta), etc. El Plan de Estabilización de 1967, que pretendió afrontar una nueva crisis económica con el consiguiente endurecimiento de las condiciones, condujo a una mayor represión del movimiento obrero, ejemplificado en la detención, en 1972, de diez líderes obreros (miembros de la ya Comisión General Coordinadora de Comisiones Obreras a nivel nacional) que serían condenados a penas de entre I2 y 20 años de cárcel, a la vez que, un año más tarde, una sentencia del Tribunal Supremo declaraba ilegal a Comisiones Obreras.

Este sería el modelo de conflictividad, de organización y de lucha que adoptaría el movimiento de enseñantes como referente cuando, a partir de i968, comenzó a dotarse de una estructura en defensa de sus reivindicaciones como trabajadores asalariados de empresas privadas o de las administraciones públicas, en especial del Ministerio de Educación. Es decir, a tomar conciencia de su condición de trabajadores de la enseñanza.

\section{El movimiento de enseñantes (1968-1977)}

El movimiento de enseñantes nació y se desarrolló en el marco social y político de la España de los sesenta y primeros setenta, formando parte del abanico de movimientos sociales (obrero, vecinal, estudiantil, de mujeres...) que se configuraron en esa década. La génesis de todos ellos estaría a medio camino entre un nacimiento espontáneo -como «necesarias» redes de solidaridad y/o de clasey la acción expresa de líderes del grupo natural, progresivamente integrados en organizaciones obreristas de corte católico (HOAC) y en organizaciones políticas clandestinas, particularmente el PCE, decidido a ampliar la base de oposición al franquismo con reivindicaciones sentidas por esos colectivos en esos años. Una intervención esta que contribuiría decisivamente a convertir en movimiento sociopolítico, como se ha dicho, la respuesta «espontánea» con que el naciente movimiento obrero se enfrentó a los miserables salarios y condiciones laborales desde los años cincuenta, y el movimiento vecinal a una especulación urbanística

\footnotetext{
hacia 1976, un sindicato «de los trabajadores [de la enseñanza] separado de los empresarios y de la Administración; para luchar por sus intereses específicos que unen al conjunto de los trabajadores y enfrentan globalmente con la patronal o con los aparatos del Estado a su servicio en una sociedad capitalista» («El sindicato de enseñanza», en Enseñanza: debate público, Madrid, 1976, pp. 245-25I, cita en p. 246). En un momento posterior e inmediato, la expresión «sindicato de clase» se utilizará para distinguirse, por parte de quienes se consideraban trabajadores de la enseñanza, de los sindicatos considerados corporativos, profesionales o no autónomos. $\mathrm{O}$, más claramente, de los que se limitaban al ámbito reivindicativo laboral y no tenían por objetivo la «aniquilación de la sociedad de clases», como se decía en la «Resolución político-sindical» aprobada por la FETE en 1976 (FETE, La U.G.T. y la enseñanza, Madrid, Akal, 1976, p. 52).
} 
que "producía» barrios para el alojamiento obrero como puros depósitos, sin unos mínimos servicios básicos. Por su parte, la lucha contra una antidemocrática sindicación obligatoria aglutinaría al colectivo universitario, que inicia entonces el futuro movimiento estudiantil. Los profesionales y, en el caso que nos ocupa, los enseñantes -también ellos previamente estudiantes, vecinos de barrios sin servicios, mujeres multitrabajadoras-, cuyo trabajo se desarrollaba en unas precarias condiciones sociolaborales, irán conformando tardía y laboriosamente su identidad como trabajadores en esas fechas.

\section{I. La «Alianza entre las fuerzas del trabajo y de la cultura» y los trabajadores de la enseñanza}

Evitando reiterar análisis ya realizados sobre el asociacionismo y el sindicalismo docente ${ }^{71}$ centraremos nuestra mirada en el «estatuto» del trabajador de la enseñanza que por estos años -entre el 67, con las primeras huelgas «como los obreros», y el 76, con la Alternativa democrática de la enseñanza- va a definir la condición docente. Un «estatuto» que, si bien respondía, tal como se esforzaron por demostrar los líderes del movimiento, a la realidad objetiva de su oficio en la España de los sesenta y setenta, necesitó ser «revelado» desde el trabajo teóricopráctico de las organizaciones políticas y sindicales de izquierda. La expresión «alianza de las fuerzas del trabajo y de la cultura» soldando una común condición trabajadora, ejemplifica la fuerza performativa que los conceptos tienen para la acción práctica.

Utilizado por Santiago Carrillo en 1967, buscando adecuar la acción y la línea del PCE a la España de ese momento (Nuevos enfoques a problemas de boy, Praga, 1967), el concepto fue difundido ampliamente en el seno de la organización en los primeros setenta, pese al recelo que despertó en muchos comunistas por considerarlo difuso, oportunista, mimético y coyuntural $7^{2}$. En todo caso, la expresión «alianza de las fuerzas del trabajo y de la cultura» actuó como instrumento operativo para organizar a los trabajadores de los sectores profesionales o «trabajadores intelectuales», buscando una confluencia superadora de la división entre trabajo manual e intelectual analizada por el marxismo clásico. Un panfleto

${ }_{71}$ Remitimos a lo dicho al respecto por Aida Terrón en dos de sus últimos trabajos: «Sistema educativo y movilización del profesorado en España: del franquismo a la transición democrática», en Montserrat, Octavio (coord.): Educación y sindicalismo de clase. El Sindicato de Enseñanza de CCOO de Asturias (1978-2013), Oviedo, KRK, 20I4, pp. 33-67, y «Coordenadas del asociacionismo profesional de los docentes...», op. cit. Asimismo, véase Hernández DíAz, José M.a.: «Associações de profesores e sindicatos em Espanha, durante a transição da ditadura de Franco para a democracia (1970-1983)», Revista Lusófona de Educação, 22 (2012), pp. 13-38.

72 Esta era asimismo la línea de raíz gramsciana, que estaba detrás del «compromiso histórico» de Berlinguer y de la necesidad de una «alianza de las fuerzas populares», más allá de un pacto entre los partidos comunista y socialista italianos, expresada por Giorgio Napolitano en 1976 en La alternativa eurocomunista. Entrevista sobre el PCI realizada por Eric. J. Hobsbawm, Barcelona, Editorial Blume, 1977, pp. 99-102. 
clandestino del Partido Socialista Unificado de Cataluña (PSUC) trataba de aclarar el sentido estricto de la formulación, tras ser calificada como propuesta «confusa» por el Movimiento Socialista de Cataluña en sus documentos internos en 1968. Decía así:

¿Qué es, pues, la alianza de las fuerzas del trabajo y de la cultura?: Es ante todo una respuesta al problema principal de la revolución socialista en los países capitalistas avanzados: ¿Cuál es el bloque de fuerzas sociales capaz de posibilitar y sostener el paso al socialismo? [...]; se trata del problema leninista de la alianza de la clase obrera [...]; en esta fase histórica nuestro partido propone resolver ese problema esencial con una novedad que se desprende del análisis de la evolución de la sociedad capitalista (incluso la española) en los últimos decenios: en esa evolución se ha producido un importante aumento, con la correspondiente influencia social, del número de asalariados que realizan un trabajo intelectual en la producción (técnicos, científicos), en los servicios (médicos, profesores, etc.) en la mediación ideológica (escritores, diseñadores, editoriales, etc.), así como de la juventud que se prepara para estos oficios (estudiantes). Esas capas son mayoritariamente asalariadas y, sin embargo, resultan en muchos países un sostén del sistema y de la propaganda capitalistas, entre otras causas porque las fuerzas socialistas de esos países no supieron ver a tiempo la importancia social de esas fuerzas de la cultura en una sociedad cada vez más, y más contradictoriamente, tecnificada. [...] Se trata de darles (a los intelectuales) consciencia de ello, de ganarles para una alianza con la clase obrera que constituya el bloque histórico capaz de instaurar y sostener el socialismo en España. A ese bloque llamamos «Alianza de las fuerzas del trabajo y de la cultura»»3.

El documento reconocía la dificultad de dar forma a esa alianza y cristalizarla en una organización que habría de ser mixta «como lo fue», decía, «la colaboración de Consejos y Partidos en la Revolución rusa». Pese a ello, los movimientos sociales conectaban claramente con estos planteamientos. Y en especial los de los profesionales -particularmente médicos, arquitectos y enseñantes-, colectivos estratégicos en la acción movilizadora por su relación con servicios básicos, susceptibles por ello de activar a los sectores populares organizados en el movimiento vecinal o de «barrios» ${ }^{7}$. Su aportación a la lucha de las barriadas populares,

73 Unidad, órgano del Comité de Barcelona del Psuc, https://ddd.uab.cat/pub/ppc/unidad/ unidad_arg68m6nSUPLi.pdf. Que la relación obreros-técnicos o profesionales e integración en un mismo partido, sindicato o movimiento social exigía algún tipo de justificación o argumentación lo muestra el prólogo de Nicolás Redondo, secretario general de la UGT, al folleto que recogía las «resoluciones» del congreso de FETE (UGT) de mayo de 1976. Tras indicar que no debía «extrañar» que estos «sindicalistas de la enseñanza» se encuadraran en la UGT, dado que sufrían la misma «explotación [...] de que son víctimas los demás trabajadores, a manos de la clase dominante y del sistema capitalista», precisaba que, más allá de las reivindicaciones relativas a sus condiciones de trabajo, su presencia en un sindicato «revolucionario» como la UGT se explicaba por su aportación a «la lucha por una mayor democracia en la educación», y a la «definición y puesta en marcha» en el sindicato, desde sus «valiosos conocimientos técnicos», de «métodos educativos y formativos adecuados» (REDONDO, Nicolás: «Prólogo», en FETE: La U.G.T. y la enseñanza, op. cit., pp. 9-Io).

74 Como se decía en 1975 en un informe sobre «la subversión en los barrios» que «emplean los grupos de oposición para conseguir derrocar al Régimen actual español», elaborado en 1975 por 
entendida como "participación técnica» en el asesoramiento para la resolución de problemas detectados por los vecinos -sanitarios, urbanísticos, educativos...-, ejemplificaba la «alianza» en una lucha que quiere ser a la vez reivindicativa y política, «transformando el papel que al servicio de los intereses oligárquicos y especulativos han cumplido en determinados momentos históricos las capas profesionales»75. Nada extraña, pues, que los colegios profesionales se convirtieran en un objetivo estratégico de la izquierda, tal como ocurrió con los de doctores y licenciados.

Artículos como el de Rosa Quitllet, publicado en 1975, mostrando a los líderes vecinales cómo llevar a cabo, con la colaboración del vecindario, un estudio riguroso sobre las carencias del equipamiento escolar del barrio y sus necesidades educativas, fundamentando las subsiguientes exigencias ante la administración, constituye un buen ejemplo del tipo de asesoramiento técnico que los profesionales de la enseñanza podían prestar al movimiento vecinal ${ }^{76}$. Allí donde este movimiento tuvo un amplio desarrollo, como en Barcelona, se llegaron incluso a constituir, en su seno, "vocalías de enseñanza» específicamente dedicadas al «conocimiento y mejora de las condiciones educativas de los barrios» ${ }^{77}$. Sus reivindicaciones, en síntesis, se centraron en la escolarización, la gratuidad, la calidad de la enseñanza y la democratización y participación en la gestión de los centros y en la política educativa municipal ${ }^{78}$.

Por otra parte, como recordaba Joan Gay al profesorado en 1975 y 1976, en plena eclosión de las huelgas de enseñantes, el «trabajador de la enseñanza» era «un trabajador asalariado» tanto si dependía del Estado como de empresas

servicios de información o policiales de la Presidencia del Gobierno, «los efectos de la labor subversiva en el Barrio son múltiples. En el Barrio confluyen los trabajadores con sus problemas en las empresas, los jóvenes con los de su educación, y los vecinos con los problemas de urbanismo, escolarización, sanitarios, transportes, mercados... etc. La mentalización es común. Todos viven los problemas de todos y la acción subversiva prospera en progresión geométrica sin riesgos para nadie, máxime si existen, como normalmente los hay, fallos y abandono en los barrios periféricos y razones de injusticia en los puestos de trabajo.

La acción es doble, ya que la corriente subversiva circula desde los lugares de trabajo, estudio y otros exteriores, a los barrios, y elaborada y discutida por todo el vecindario regresa a sus orígenes para exhibir soluciones, [...], predisponiendo a la masa en contra de las autoridades».

$\mathrm{El}$ «resultado final» se añadía, en este informe con abundantes datos y gráficos demostrativos de esa «progresión geométrica» de la propaganda «subversiva» entre I970 y 1974, la «formación de organismos paralelos para encuadrar la masa» y el desplazamiento de las «autoridades» oficiales por dichos organismos para la solución de los problemas del barrio (Plan barrios. Estudio sobre la subversión en los barrios, enero de 1975, documento policopiado, 25 pp. y I2 anexos, citas en pp. 2-3, archivo de los autores).

75 Rebollo, Rodríguez y Sotos: El movimiento ciudadano ante la democracia, Madrid, Cenit, 1977 , p. 40.

${ }_{76}$ Quitllet, Rosa: «Escuelas y barrios», Cuadernos de Pedagogía, 3 (1975), pp. 4-9.

77 Miembros de vocalías de enseñanza de aA. vv. De Barcelona: «Las Asociaciones de vecinos y su intervención en la enseñanza», Cuadernos de Pedagogía, I8 (1976), p. Io.

${ }_{78}$ Carbonell, Jaume: «De la Ley General de Educación a la alternativa de la escuela pública. Algunas notas introductorias sobre los movimientos sociales en el sector de la enseñanza», Revista de Educación, número extraordinario (1992), pp. 237-255 (pp. 245-248). 
privadas $^{79}$. Una condición, la de asalariado, ocultada por alusiones al carácter vocacional de su tarea, la relevancia de su misión, el ideal de servicio a la sociedad o su consideración como profesional más o menos autónomo. Sin embargo, la conversión del profesional en un "técnico asalariado", que vende su cualificada fuerza de trabajo a cambio de un salario le iguala, decía, «al resto de los trabajadores». En «una primera fase» se resiste «a abandonar» su estatus de profesional y «busca solucionar sus problemas individualmente». A la larga, su condición de trabajador asalariado le imponía la necesidad de aceptar «la forma sindical como una forma de defensa mejor» de sus intereses. Una vez interiorizada dicha condición, habiendo tomado conciencia de ella, el «sindicalismo de técnicos» podía decantarse, bien por su autonomía «con respecto al resto de los trabajadores, siguiendo todavía el modelo profesional-corporativo, bien en colaboración o totalmente integrados en las organizaciones sindicales del movimiento obrero». «En el momento actual», concluye,

la necesidad de un sindicato único de enseñantes, que más adelante decidiría en qué condiciones se integra en el sindicalismo del resto de trabajadores, tendría que ser la perspectiva que impulsara cualquier planteamiento a corto plazo de la organización y defensa colectiva de intereses laborales y profesionales, ya se desarrolle a través de las estrecheces de la Administración y del sindicalismo oficial o se ampare en las posibilidades de los Colegios profesionales o de otro tipo de asociaciones ${ }^{80}$.

La publicación de textos como los indicados no era baladí. Cuando los estudiosos del fenómeno analizan la gestación del movimiento de enseñantes en España señalan la dificultad de los docentes de todos los niveles educativos para superar el sentimiento de distinción con el resto de los trabajadores y para adoptar sus modelos de conflictividad, organización y defensa. Ello exigía una determinada actitud individual -la ruptura con el miedo, tras la depuración y sus consecuencias, y la superación de los condicionantes ideológicos «pequeñoburgueses» que les caracterizan-. Más allá de ello, esta adhesión surgirá, en todo caso, como consecuencia de factores estructurales que condujeron a la proletarización de un colectivo que encontrará en el ejemplo de la clase obrera un factor decisivo para su propia movilización.

\subsection{El movimiento de enseñantes}

Entre 1965 y 1975 -una fase de represión, crisis y reorganización del movimiento obrero- se constituye el movimiento de enseñantes. Sus primeras acciones serán dinamizadas por un pequeño grupo de licenciados, militantes o simpatizantes (p. I4).

79 GAY, Joan: «Los trabajadores de la enseñanza», Cuadernos de Pedagogía, 4 (1975), pp. I4-I7

8o GAY, Joan: «La organización de los trabajadores de la enseñanza y la defensa colectiva de sus intereses», Cuadernos de Pedagogía, I3 (1976), pp. 20-24 (pp. 20, 21 y 24). 
de organizaciones de la esfera comunista o socialista y del obrerismo católico, que trabajan como docentes en la enseñanza privada, algunos de los cuales habían participado en las revueltas estudiantiles de los años precedentes. En simetría con la acción desarrollada por las nuevas y embrionarias organizaciones de clase que estas mismas fuerzas promueven -las comisiones de obreros- comenzarán entonces a trasladar a sus propias empresas -colegios privados- los métodos de lucha propios de los trabajadores y a adoptar sus modalidades organizativas y reivindicativas: comisiones de enseñantes; «entrismo» en el Sindicato Vertical de Enseñanza, creado en 1964; asambleas en iglesias; elaboración de manifiestos y plataformas reivindicativas; coordinación con movilizaciones en otros sectores -padres, estudiantes...-; utilización de espacios legales como los Colegios de Doctores y Licenciados, etc.

En 1968 -coincidiendo con un importante ciclo huelguístico en el cinturón de Madrid- la enseñanza privada, un sector subproletarizado sin ordenanza y/o convenio colectivo que regule su situación laboral, hará en Madrid la primera huelga del sector, con alcance limitado, pero con alta resonancia por ser la primera vez que se hace una huelga «como las de los obreros». Un año después, el primer convenio provincial de la enseñanza privada de Madrid es considerado un fruto maduro de esa huelga y, a su vez, de la actividad organizativa desplegada desde tres años antes por un pequeño núcleo de docentes procedentes de movimientos católicos y organizaciones del movimiento estudiantil. Organizados en torno a una escuela de Sociología independiente, CEISA, bajo el formato de «Seminario de Pedagogía» realizan un trabajo de tipo teórico a la vez que «formulan una plataforma reivindicativa para la enseñanza privada y exigen que sea refrendada en convenio colectivo». En ella se contemplan las consignas que pretenden movilizar al colectivo en los años siguientes: unificación de las condiciones salariales para todos los enseñantes -maestros y licenciados- y supresión de las artificiales categorías dentro de un mismo ciclo de la enseñanza en la perspectiva de un cuerpo único de enseñantes; reglamentación de las condiciones de trabajo y adscripción a una seguridad social plena; funcionamiento democrático de los centros, y acuciante exigencia de incremento salarial ${ }^{8 \mathrm{r}}$.

Al mismo tiempo, sumado a ello, el fracaso de la implantación de la Ley General de Educación de 1970 en relación con las expectativas creadas, así como la contrarreforma educativa llevada a cabo en los últimos años del franquismo desde el mismo régimen político, convirtió su aplicación en «un volcán de contradicciones y conflictos $»^{82}$. Entre ellos, el incremento del ya numeroso colectivo de profesores no numerarios (PNN: contratados e interinos) en la enseñanza secundaria, condición que en el curso 1972-73 llegó a alcanzar al $; 76,7 \%$ ! del profesorado. La primera huelga de PNN de bachillerato tendría lugar en 1969 y unos años después (enero-febrero de 1973) se plantearía, a escala estatal, en la enseñanza primaria o básica. Un sector este último en el que existía un descontento generalizado por

${ }^{8}$ PÉRez, Magdalena y Doz, Javier: «El movimiento de los enseñantes en España», Zona Abierta, 7 (1976), pp. 49-66 (p. 60).

${ }_{82}$ Carbonell, Jaume: «De la Ley General de Educación...», op. cit., p. 237. 
el agravio comparativo que significaba, en relación con otros cuerpos docentes y no docentes, un coeficiente retributivo no acorde con su titulación, en especial cuando la reforma de i97o le había conferido un grado universitario, y en el que el profesorado no numerario se incrementaría como consecuencia de la progresiva implantación de la educación general básica.

La conflictividad -manifiestos, huelgas, encierros, movilizaciones, concentraciones, manifestaciones, asambleas, etc.- entre el profesorado fue en aumento a partir de 1970, dando lugar a la progresiva configuración de comisiones, plataformas o coordinadoras de centro, barrio o zona, localidad, comarca, provincia o de ámbito estatal, compuestas por representantes elegidos por cada uno de los diferentes colectivos; es decir, a la constitución de estructuras representativas temporales, más o menos estables y amplias, que dieron una cierta forma organizativa al movimiento de enseñantes ${ }^{83}$.

El primigenio carácter asambleario de estas formas organizativas, y su dimensión territorialmente expansiva, plantearon de inmediato, por su propia evolución, el debate acerca de la unidad o pluralidad, ya se tratara de una pluralidad territorial, por categorías docentes o niveles educativos, sectorial -público/privado- o ideológico-política. En suma, el debate acerca de la unidad o pluralidad del futuro sindicalismo docente, toda vez que una de las reivindicaciones fundamentales del movimiento de enseñantes era, frente al Sindicato Vertical de la enseñanza o la afiliación obligatoria al Servicio Español del Magisterio, la libertad sindical. Y, en relación con ello, su inserción o no en las futuras organizaciones sindicales de la clase obrera y sus relaciones con el movimiento vecinal entre otros.

La ausencia de libertades políticas y sindicales forzó a buscar vías alternativas dentro del marco legal de la Ley de Asociaciones de 1964 y de las organizaciones obreras o estudiantiles católicas, para asociarse con fines reivindicativos o simplemente de discusión, estudio o encuentro y difusión de experiencias pedagógicas. Así, surgieron, en distintas provincias y en el ámbito de la enseñanza primaria, las Asociaciones de Antiguos Alumnos de las Escuelas Normales, a finales de la década de los sesenta; la freinetiana Asociación para la Correspondencia y la Imprenta Escolar (ACIES) - el I Encuentro sobre las técnicas Freinet tendría lugar en 1969 y la asociación se fundó en 1974 cambiando su nombre en 1977 por el de Movimiento Cooperativo de Escuela Popular (MCEP)-, y, abiertas al profesorado de otros niveles, las Escuelas de Verano, tras una primera organizada por la Institución «Rosa Sensat» en 1966 en Barcelona. Y, en otros niveles de enseñanza, los Grupos Obreros de Estudios Sociales (GOEs), creados en Madrid en el seno de la HOAC, como un «aula popular» para «el estudio de los problemas y de las cuestiones que interesan a la Clase Obrera en general o a los miembros de GOES en particular a fin de ayudarse mutuamente en la formación de los criterios orientadores de la

${ }_{3}$ Un análisis pormenorizado de esta conflictividad puede verse en Espinosa, Antonio: «Algunos materiales para el análisis de la conflictividad docente (I978-I988)», en PANIAGUA, Javier y SAN Martín, Ángel (eds.): Diez años de educación en España (1978-1988), pp. 363-404 ("Anexo cronológico I. La conflictividad docente 1970-1977»). 
promoción obrera», según se decía en el punto primero del proyecto de sus «bases normativas» ${ }^{84}$. O, como ya se ha dicho, los Colegios de Doctores y Licenciados u organizaciones tales como el Club de Amigos de la Unesco. Todo ello en un contexto de proliferación de editoriales, revistas y publicaciones que no solo ponían al alcance del profesorado los autores y tendencias revolucionarias, reformistas o innovadoras en el ámbito de la educación y la pedagogía, sino que servían, al mismo tiempo, de plataforma para la difusión de sus propuestas e ideas al respecto ${ }^{85}$. Propuestas e ideas que emergerían en forma de «alternativas» colectivas al sistema. Una denominación, la de «alternativa», que, como diría años más tarde una de sus promotoras, se aplicó «a una serie de ideas, propuestas y principios progresistas, que surgieron casi simultáneamente», a partir «de los años 1969 o 1970» en «distintos puntos del país, respecto a cuál sería el sistema educativo para el futuro democrático en España» ${ }^{86}$.

\subsection{La explosión de las alternativas (1975-1977)}

«Hay dos años que se inscribirán con letras de oro en nuestra historia de la educación: 1975 y $1976 »^{87}$. Fueron los años, sobre todo 1976, de elaboración y publicación de diferentes «alternativas» en el ámbito de la enseñanza, aunque puedan encontrarse precedentes de este tipo de documentos, como el libro anónimo titulado La enseñanza en España, publicado en París en I970, resultado de discusiones colectivas de miembros del PCE, y escrito por dos futuros miembros del Equipo de Estudios (EDE) dirigido por Fernández de Castro ${ }^{88}$, en cuyo capítulo final se efectuaban ya una serie de «propuestas para una transformación radical» de la enseñanza en España tras «el derrocamiento de la dictadura» ${ }^{89}$.

El 31 de enero de 1976, con la asistencia de unos i.80o socios, la Asamblea General del Colegio de Doctores y Licenciados madrileño aprobaba un documento titulado "Alternativa para la enseñanza. Bases para una discusión», al que habían precedido un «Documento Verde» del mismo título, presentado un año antes en la asamblea general, y otro texto titulado «Socialización, otra alternativa para la educación», elaborado por un grupo de enseñantes católicos progresistas. El resultado final, tras debates y discusiones, fue un documento no exento de

\footnotetext{
${ }_{4}$ «Bases» reproducidas en Bozal, Valeriano: Una alternativa para la enseñanza, Madrid, CENTROPRESS, 1977, pp. 76-77.

${ }_{5}$ Véase, para más detalle, Lázaro, Luis Miguel: «Política y educación: la renovación pedagógica en España, I970-1983», en Candeias Martins, Ernesto (coord.): Actas de V Encontro Ibérico de História da Educação. Renovação Pedagógica, Coimbra. Castelo Branco, Alma Azul, 2005, pp. 347-394.

${ }_{86}$ O’Malley, Paloma: «La Alternativa», Revista de Educación, número extraordinario (1992), pp. 325-337 (p. 328).

${ }_{87}$ Carbonell, Jaume: «De la Ley General de Educación...», op. cit., p. 252.

88 FERnÁNDEZ DE CASTRO, Ignacio: Reforma educativa y desarrollo capitalista. Informe crítico de la Ley de Educación, Madrid, Edicusa, 1973, p. 2II.

89 Anónimo: La enseñanza en España, Paris, Éditions de la Librairie du Globe, 1970, p. I52.
} 
«imprecisiones y matizaciones» debidas, a juicio de una de las protagonistas del mismo, al

pluralismo [ilegal en aquellos momentos] en que se había elaborado, ya que en este proyecto además del PSOE y FETE-UGT, el PCE y CCOO de la enseñanza, estuvieron presentes y activos la Unión Sindical Obrera (USO), la Organización Revolucionaria de Trabajadores (ORT) y el Movimiento Comunista de España (MCE) ${ }^{90}$.

También en 1975, el Colegio de Doctores y Licenciados de Valencia había aprobado otra «Alternativa para la enseñanza en el País Valenciano»; el Seminario de Pedagogía de este Colegio publicaba en forma de libro Por una reforma democrática de la enseñanza; y la Asamblea general de la x Escola d'Estiu de Barcelona aprobaba una «declaración»-«Per una nova escola pública»- a la que seguiría otra en 1976, en la xi Escola d'Estiu -«Per una nova escola pública catalana»-. A estos documentos seguirían otros similares, circunscritos en unos casos al ámbito universitario y en otros de índole general, obra de diversos colectivos de enseñantes cristianos de base, de partidos como el socialista -en este caso elaborado por Luis Gómez Llorente, vicedecano del Colegio de Doctores y Licenciados madrileño ${ }^{91}-$ o el comunista ${ }^{92}$, o de otros colegios de doctores y licenciados y de asociaciones de enseñantes aprobados en escuelas de verano, congresos o jornadas de estudios ${ }^{93}$. En síntesis, existía una conciencia más o menos generalizada de

90 Lucendo, Pilar: «El Colegio de Doctores y Licenciados (I973-1976)», en García Santesmases, Antonio y De la Rocha Rubí, Manuel (coords.): Luis Gómez Llorente: educación pública y socialismo, Madrid, Los Libros de la Catarata, 2013, pp. IIo-II4 (pp. II2-II3). En igual sentido se expresa Javier Doz en la entrevista recogida en VARELA, Julia: Las reformas educativas a debate (19822006), Madrid, Morata, 2007, pp. I68-169, destacando la mayor influencia del PSOE y del PCE en el documento final y el hecho de que ambos partidos mantuvieran, en el seno del Colegio de Doctores y Licenciados madrileño, «una alianza [...] que no era frecuente en aquellos años en otros ámbitos».

91 Gómez Llorente, Luis: «Enseñanza y socialismo», en EQuipo Jaime Vera: La alternativa socialista del P.S.O.E., Madrid, Cuadernos para el Diálogo, I977, pp. I07-I36. En palabras de Victorino Mayoral, Gómez Llorente «no fue el ministro de Educación que todos esperábamos y deseábamos» -en el PSOE- «en el primer gobierno socialista salido de las urnas en I982» [«La alternativa socialista a la educación», en García Santesmases, Antonio y De la Rocha Rubí, Manuel (coords.): Luis Gómez Llorente..., op. cit., p. I27]. Se trata de una errónea apreciación: no «todos» en el PSOE esperaban o deseaban ver a Gómez Llorente al frente del Ministerio de Educación. Razones ideológicas aparte, en el congreso extraordinario del psoe de septiembre de 1979 había encabezado la candidatura a la Comisión Ejecutiva que se había enfrentado a la liderada por Felipe González. Además, no era profesor universitario.

${ }_{92}$ O’Malley, Paloma (coord.): Anteproyecto de alternativa democrática a la enseñanza, Madrid, Cénit, 1977.

93 La mayoría de estos documentos, junto con declaraciones críticas eclesiásticas, se recogieron en Bozal, Valeriano: Una alternativa..., op. cit., pp. 182-299, y, de un modo un tanto confuso, en $\mathrm{SE}_{\mathrm{E}}$ minario De EdUCACión: Enseñanza: debate público, op. cit. Sobre las «alternativas», remitimos a los trabajos ya mencionados de O’Malley, Paloma: «La alternativa», pp. 330-336; CARbonell, Jaume: «De la Ley General de Educación...», pp. 252-254, y LÁzaro, Luis Miguel: «Política y educación: la renovación pedagógica en España, 1970-1983», pp. 364-373, así como a los de BozAL, Valeriano: «Una alternativa para la enseñanza», en Por la escuela pública. Homenaje a Mariano Pérez Galán, Madrid, Fundación CIVES, 1998, pp. 47-56, y Groves, Tamar: Teachers and the Struggle for Democracy in Spain, 1970-1985, New York, Palgrave MacMillan, 20I4, pp. IOI-I08. 
que la nueva situación política, aún por configurar, implicaba, o hacía posible, un nuevo sistema educativo. De ahí que surgieran diversas alternativas y contraalternativas cuyas propuestas influirían ya en 1976, pero sobre todo en la primera cita electoral de 1977, en los programas presentados por los nuevos partidos políticos y sindicatos de profesores.

En relación con las cuestiones que venimos analizando, los temas más controvertidos en las alternativas fueron el paso de un sistema jerarquizado de cuerpos y categorías docentes a un cuerpo único y de un sindicalismo vertical a otro democrático, y la disyuntiva, para los docentes del sector público, entre la funcionarización y el contrato laboral94. La cuestión sindical planteaba asimismo otros dilemas:

- Si, una vez declarada la libertad sindical y el fin del sindicalismo oficial, se optaba por un único sindicato o por la pluralidad de sindicatos.

- Si el sindicato o sindicatos de enseñanza se insertaban o no en el futuro sindicalismo obrero donde también se debatía, en ese momento, si era preferible un sindicato unitario de base asamblearia o la pluralidad sindical.

- Si el sindicato o sindicatos iban a ser, o no, solo de enseñantes. Es decir, si se permitía la afiliación de otros trabajadores de la enseñanza no docentes.

- Si se iba a tratar de un sindicato o sindicatos solo o primordialmente reivindicativos o también, sobre todo, de un sindicalismo sociopolítico preocupado por la gestión democrática del sistema e instituciones educativas y, desde una perspectiva más general, por la transformación de la sociedad en una dirección socializadora.

- El carácter obligatorio o voluntario de la afiliación sindical y, en el segundo caso, la articulación de las relaciones con los docentes no afiliados.

- El paso constituyente desde una situación en la que predominaba la existencia de diversas plataformas, comisiones y coordinadoras de representatividad y base asamblearia al nuevo sindicato unitario, y la configuración interna del sindicato o sindicatos, si se admitía la pluralidad organizativa, en una línea más o menos asamblearia.

- La articulación territorial de ese nuevo sindicalismo, en especial en relación con las comunidades autónomas consideradas nacionalidades.

¿Cuáles fueron las propuestas o posiciones más generalizadas entre las distintas «alternativas» o «declaraciones»? Puede resultar paradójico a primera vista que la petición de libertad sindical figurara junto a la propuesta de un sindicato unitario en el que se reconociera la existencia de diversas tendencias, y en el que, en definitiva, no solo existiera unidad de acción -posible, mediante acuerdo, en una situación de pluralidad sindical-, sino también unidad organizativa. No se veía una posible contradicción, en aquellos momentos, entre ambas reivindicaciones. Había dos razones. Por un lado, la desaparición del sindicalismo vertical estatal era un requisito previo a cualquier otra consideración o propuesta. Por otro, la unidad sindical se planteaba como «una meta a conseguir por la libre voluntad

94 Carbonell, Jaume: «De la Ley General de Educación...», op. cit., pp. 244-245. 
de todos, y no un punto de partida impuesto»95. Las diferencias en el seno de la Comisión de la Alternativa madrileña encargada de desarrollar este punto -y en otras alternativas- se centraron sobre todo «en los pasos a dar para la consecución de un sindicato unitario, sobre la forma de llegar a un congreso sindical constituyente unitario y los plazos necesarios para ello» ${ }^{96}$, una vez que esta era la opción asimismo generalizada. La fórmula usualmente empleada para caracterizar a ese nuevo sindicato sería la de unitario, democrático, reivindicativo e independiente de los partidos políticos, el Estado, la Iglesia católica o la patronal. Una caracterización que admitía desarrollos -la Alternativa valenciana y las «declaraciones» de las x y xi Escolas d'Estiu integraban, por ejemplo, a dicho sindicato único en un sindicato asimismo único de trabajadores-, aclaraciones o matices, a la que en ocasiones se añadían expresiones o términos tales como «horizontal», «de clase», «de libre sindicación», «sociopolítico» o «apartidista pero no apolítico». Las funciones que se asignaban a este nuevo sindicato iban desde las reivindicativas de índole laboral e intervención en las negociaciones sobre salarios y condiciones de trabajo, en relación tanto con el personal docente como no docente, hasta el control de los contenidos y estructura del sistema educativo y participación en los organismos ejecutores de la gestión y política educativa, pasando por la formación permanente del profesorado y la colaboración y acción común con sindicatos de otros sectores productivos, organizaciones de barrios y asociaciones de padres y de alumnos ${ }^{97}$.

La opción, en el sector público, entre funcionarización o contrato laboral -una cuestión clave, como se verá, en la evolución posterior de los acontecimientos- se dejaba por la Alternativa madrileña para una discusión posterior ${ }^{8}$. No sucedía lo mismo sobre la reivindicación del cuerpo único de enseñantes. Su exigencia tenía dos fundamentos: el principio de «a igual trabajo»-léase docente de cualquier nivel o modalidad- «igual salario» y la propuesta de un ciclo único desde los cuatro a los dieciocho años. Ambos presuponían la igualdad formativa -universitaria- de todos los docentes, y la ausencia de distinciones entre enseñanza pública-privada, maestros-licenciados o profesores numerarios-no numerarios. La diferencia, según que la propuesta tuviera uno u otro fundamento, residía en que el primero incluía en el cuerpo único al profesorado universitario mientras que el segundo lo excluía. De ahí que en el desarrollo de la Alternativa madrileña, llevado a cabo en junio de 1976 en las I Jornadas de Estudio sobre la Enseñanza, se aprobaran, en este punto, dos ponencias distintas según que se optara por una u otra propuesta ${ }^{99}$.

95 «Socialización, otra alternativa para la enseñanza», en Enseñanza: debate público, op. cit., pp. 70-8I (cita en p. 80).

96 Bozal, Valeriano: Una alternativa..., op. cit., p. 177. El texto corresponde a las «conclusiones» (pp. I6I-179) de las Primeras Jornadas de Estudios sobre la Enseñanza, llevadas a cabo en Alcobendas (Madrid) en junio de 1976 con el fin de desarrollar la Alternativa madrileña.

${ }_{97}$ Ibid., pp. I24-I25.

$98 \quad$ Ibid., p. 122.

$99 \quad$ Ibid., pp. I72-I77. 
Es conocida, y ha sido estudiada, la evolución posterior del sindicalismo docente en España ${ }^{\text {10o }}$. La libertad sindical condujo tanto en el mundo obrero como en el de los enseñantes a la pluralidad de sindicatos. Podría existir en el futuro, en determinados momentos y ante determinados temas, unidad de acción, pero no unidad organizativa. Quien primero iniciaría la carrera sindical por la afiliación independiente sería la FETE tras refundarse en el congreso de Cádiz de 1976. En la «Resolución político-sindical» aprobada en dicho congreso, junto con su «alternativa» y su «declaración» socialista sobre la enseñanza, se reconoce, por un lado, que la unidad orgánica sindical favorecía la «eficacia» del movimiento obrero, y que solo ella haría posible la «emancipación definitiva» de los trabajadores y la «eliminación de la sociedad de clases». Sin embargo, al mismo tiempo se afirmaba que dicha unidad debía construirse desde la libertad y no desde la imposición. Y, descendiendo ya a la realidad, que ese podía ser el ideal, pero que «en la actualidad» había «dos hechos incontrovertibles: la voluntad de unidad del Movimiento Obrero y la pluralidad de organizaciones sindicales existentes ${ }^{\text {10r. }}$. En consecuencia, la FETE se definía como un sindicato de clase, democrático, autónomo y libre, pero no como un sindicato unitario, aunque, eso sí, abierto a todos los trabajadores de la enseñanza que desearan afiliarse al mismo. Planteada de esta forma la carrera por la afiliación sindical, tras la FETE, y no sin debate y discusiones sobre su naturaleza, se fundarían en 1978, con vocación asimismo unitaria y de clase, la Federación de Enseñanza de Comisiones Obreras y la Unión Confederal de Sindicatos de Trabajadores de la Enseñanza, a los que seguirían otros sindicatos, asociaciones o federaciones de diferente signo.

\section{La excepción anarquista-libertaria}

¿Y el anarquismo libertario? ¿Cuál era la posición de este movimiento que tanto supuso antes de 1939 en el mundo de la educación y de la cultura obrera? Una de las principales diferencias o contrastes entre ese antes y ese después, es el menor protagonismo del discurso y las prácticas libertarias, en correspondencia con un protagonismo social, sindical y político también menor. Su posición automarginal en el debate de las alternativas se reflejaría en un libro editado en 1977, titulado Por un aprendizaje libertario, que recogía diversos escritos y documentos del sindicato de enseñanza de la CNT, el cual no solo no planteaba una alternativa más, sino que, en nombre de la autogestión educativa, rechazaba la alternativa del Colegio de Licenciados madrileño por su centralismo estatal, así como cualquier otra propuesta destinada a reforzar el «sistema» de enseñanza cuando toda su «lucha» iba dirigida a la «destrucción del mismo sistema de

roo Véase Terrón, Aida: «Sistema educativo y movilización del profesorado...», op. cit., y Jiménez JaÉn, Marta y Marrero Morales, Manuel: «Historia de los Sindicatos de Trabajadores de la Enseñanza», en Sindicato de Trabajadores de la Enseñanza: Sindicalismo autónomo y asambleario de la enseñanza. 25 años (y más) de STEs, Madrid, Confederación de STEs, 2003, pp. 9-138.

ror FETE: La U.G.T. y la enseñanza, op. cit., pp. 53-55. 
enseñanza» como «institución diferenciada» y, en particular, a «la desaparición de los cuerpos profesorales y tecnocráticos» con el fin de convertir la enseñanza en «libre aprendizaje» ${ }^{102}$. Las alternativas propuestas solo pretendían, se decía, sustituir una coacción por otra, olvidando que «el capital y el Estado no son sino modalidades diferentes de un mismo poder».

Tales alternativas no eran más que una «nueva Iglesia secularizada» ${ }^{103}$. Frente a ellas, la CNT defendía una enseñanza antiautoritaria, autogestionada, no obligatoria, asamblearia y libre; es decir, basada en el mutuo acuerdo y el apoyo solidario entre comunidades de aprendizaje libres y en experiencias marginales, no directivas o autónomas.

Sus reflexiones teóricas pueden ejemplificarse en la obra El Manifiesto libertario de la enseñanza de Carlos Díaz, publicado en $1978^{104}$, que comienza negando el carácter autogestionario o libertario de los «falsos profetas» de la pedagogía permisiva o neorrusoniana (Summerhill, Rogers, el paidocentrismo), llegando hasta el rechazo del cooperativismo. «Dentro del capitalismo», afirma, "es imposible la autogestión porque» subsisten el «Estado de clase», «el aparato ideológico del Estado», «la propiedad privada de los medios de producción», «el sistema de lucro, plusvalía y expolio», «la lucha de clases», «el binomio dirigentes-dirigidos», «la llamada división "social” del trabajo», «la "democracia indirecta”, forma de no-democracia», "la mentalidad de consumo, lucro, egoísmo» y «el capitalismo internacional» ${ }^{\mathrm{10}}$.

Solo puede concebirse «la autogestión en el marco del socialismo», pero no de «cualquier socialismo». No, desde luego, del «socialismo verticalista, autoritario, centralista» porque deja «intacto el aparato del Estado», con sus comisarios políticos y comité de depuradores. Esto es el estalinismo y el «socialismo en un solo país», al que en otro momento define como «socialismo de Estado», para el que la «supuesta autogestión sería un medio, y nunca un fin en sí mismo». Un medio para «mantener la verticalidad, el estatismo, el partido en el poder, el viejo rollo del poder. Distintos personajes, el mismo escenario» ${ }^{106}$. De ahí los principios básicos de la enseñanza libertaria: horizontalismo; asambleísmo; descentralización; policentrismo coordinado y confederado; trabajo rotativo frente a la división social del trabajo; autonomía y apertura e inserción en la comunidad y el entorno tanto de la escuela como del profesor; estudio científico del niño; horarios flexibles;

${ }_{102}$ Por un aprendizaje libertario. Escritos y documentos del sindicato de enseñanza de la CNT, Madrid, Campo Abierto, I977, pp. 2IO-2II y 3I-32.

${ }_{103}$ Ibid., pp. 23, 26, 35 y 43.

${ }_{104}$ Díaz, Carlos: El Manifiesto libertario de la enseñanza, Madrid, La Piqueta, i978. El autor decía ser, cuando escribió esta obra, catedrático de Filosofía de Bachillerato y profesor no numerario de universidad. Asimismo, declaraba no pertenecer a la CNT. Sus publicaciones, en esa época, se movían en el ámbito del personalismo de Mounier y el anarquismo y, en general, aparecían en editoriales católicas, sobre todo en la editorial Zero de la HOAC, fundada en 1946, en la que ya había publicado en 1970 El niño proletario, un folleto escrito a partir de la lectura de El alma de el niño proletario de Otto Rühle editado en I92I.

ios Ibid., p. 22.

106 Ibid., pp. I9-2I. 
recurso a las técnicas Freinet y presencia relevante del trabajo manual; control no unilateral y vertical, sino múltiple y recíproco; inspección rotativa; cuerpo único de profesores sin categorías, y desescolarización, desaparición del aula, «en favor de la comunidad en marcha en un proceso educativo sin fin. Desescolarizar la escuela es nuestra meta, para hacer, de toda la comunidad, escuela», en la línea preconizada por Illich, desde Cuernavaca, y Reimer, entre «tantos otros» ${ }^{107}$. El descenso desde los principios y propuestas a la realidad de la época -huelga del profesorado no numerario de 1976-77- no podía ser más duro: se trataba de una huelga que «so pretexto de comerse al mundo y arrumbar lo caduco en el terreno educativo" ha finalizado "por ser lo más reaccionario, estomacal y pobre en cuanto a postura alternativa» ${ }^{108}$.

\section{6. ¿Reformismo o ruptura? Otras propuestas, visiones y revisiones}

¿Cómo considerar las alternativas o declaraciones mencionadas? ¿Se planteaban como un instrumento para la consecución de una sociedad socialista o, al menos, de una «república democrática de trabajadores de toda clase» como se definía a España en al artículo primero de la Constitución de I93I? ¿Significaban las alternativas, y en concreto la madrileña, una ruptura con el sistema educativo existente o una reforma del mismo? ¿Pretendía, tal y como se le achacó desde el sector eclesial y la derecha política, instaurar un modelo estatista-marxista de enseñanza? ¿Qué juicio o valoración posterior mereció a sus mismos protagonistas, o a personas ideológicamente afines, una vez constatada la «inermidad» o aplicación desvirtuada de sus propuestas fundamentales?

Es innegable que, en general, dichas alternativas y declaraciones suponían una transformación radical en la estructura, funcionamiento y gestión del sistema educativo existente. Las diferencias surgen, con matices y ambigüedades, al referirse a la

${ }_{107}$ Ibid., pp. 28-29. Las referencias a Illich no son gratuitas. Sus publicaciones sobre la sociedad y la educación desescolarizadas eran ampliamente conocidas en la España de los años $70-L a$ sociedad desescolarizada andaba ya por la $3 .^{a}$ edición en 1976 . Nada tiene de extraño que sus tesis encontraran un amplio eco en los sectores libertarios, tanto en lo relativo a las críticas a la escolaridad -pública o privada, capitalista o socialista- en sí misma, o la consideración de la educación como una mercancía con su valor de cambio, como en la conversión del mundo en una gran aula [«Conversando con Ivan Illich», Cuadernos de Pedagogía, 7-8 (1975), pp. 16-23]. Tampoco lo es que hoy, cuando se escriben estas páginas, el segundo ítem que figura en la web del sindicato de enseñanza de la CNT trate sobre «las familias y las experiencias de educación alternativa. La desescolarización y el aprendizaje activo contado por las familias»: www.cnt.es/categoria/temas/enseñanza (consultado el I2 de noviembre de 20I7).

${ }^{108}$ Ibid., p. 48. Seguidamente incluye la carta enviada a un amigo del sindicato de la enseñanza de la CNT, y publicada en las revistas Aprendizaje de la CNT y Pastoral misionera, donde califica la huelga de «gremial» en exclusiva búsqueda de la estabilidad, así como de «vulgar, habichuelera, pesetera, burguesa hasta el hígado» tanto de unos como de otros. Ni rastros, dice, de «lucha» por «la igualdad socialista interclase sin castas» en defensa del «cuerpo único sin categorías». En una adenda a dicha carta de marzo de 1978 concluye: «Todo sigue igual, amigo. Consumatum est. Habéis demostrado que no queríais más que la habichuela. Que su flatulenta digestión os aproveche y durmáis el sueño de los justos desde cualquier sindicato vertical nuevo» (pp. 54-57). 
naturaleza y alcance de dicha transformación. En un extremo se sitúan aquellas alternativas con alusiones expresas a una futura sociedad socialista, o a la desaparición de la sociedad de clases hacia las que se dirigían las propuestas efectuadas ${ }^{109}$. En otro, aquellas en las que nada se dice al respecto. En este punto, la Alternativa madrileña afirma que la propuesta que se realiza no es utópica, sino que responde a la «realidad política, social y económica» del país: la de «un sistema capitalista que no consigue sacar adelante la reforma capitalista de la enseñanza». Esa es la razón por la que la alternativa que se propone «no puede [...] ser pensada como un nuevo intento de reforma», de una reforma que «se ha demostrado imposible por las contradicciones del capital». Un «capital» que no aceptará ni apoyará una «verdadera alternativa a la enseñanza». La «lucha» por la alternativa es algo que corresponde a «los directamente interesados en ella -profesores, alumnos, padres-», y, «en un sentido más amplio» a «todos los trabajadores», pues «esta transformación de la enseñanza se inscribe en el marco de una transformación global que abandone la lógica del beneficio privado para entrar en la lógica del trabajo, en la lógica de la utilidad social». Si ese «beneficio privado» y la referencia a ambas «lógicas» se referían solo al ámbito de la enseñanza o a toda actividad social y económica, es algo que no se concreta.

«La perspectiva en la que se pensaba la Alternativa era la ruptura, no la continuidad», afirma Valeriano Bozal en un texto publicado veintidós años más tarde, en I99 ${ }^{\text {Iо }}$, aunque también dijera que «la Escuela Pública sería, a la vez, instrumento y factor de consolidación de esa ruptura (no violenta), mientras que el mantenimiento de un doble sistema -enseñanza estatal y enseñanza privada-, era testimonio de continuidad». La razón de ello se debía a que, aunque «la Alternativa no se planteó cruzada alguna contra la enseñanza privada» optando por «respetar su existencia», se confiaba en que la expansión de la primera hiciera que la segunda fuera perdiendo «sentido de manera gradual»" Como el mismo Bozal cree recordar, pese a «su uso político en aquellos años», no solo «la palabra “ruptura” no aparece en el texto de la Alternativa», sino que «nadie» la utilizó «en el curso de los debates que la posibilitaron», para concluir, «con la perspectiva histórica» que en i998 tenía de lo después acaecido -es decir, de la evolución de los hechos en un sentido opuesto a lo allí propugnado-, que «valorada la Alternativa en la actualidad [...] la ruptura era el horizonte adecuado» ${ }^{\mathrm{In}}$. $\mathrm{O}$, si se prefiere, que para llevar a la práctica lo que en ella se proponía era indispensable la ruptura.

ro9 Por ejemplo, la que, con el título de «El sindicato de enseñanza» se recoge en las pp. 247-251, con una atribución o autoría confusa, en Enseñanza: debate público, o en «la alternativa» y «la declaración» socialistas sobre la enseñanza aprobadas en el congreso de la FETE de 1976 (FETE: La U.G.T. y la enseñanza, op. cit., pp. 38, 49, 52 y 68-69, entre otras).

по Bozal, Valeriano: «Una alternativa para la enseñanza», op. cit., p. 53. Bozal formó parte como «independiente» de la junta directiva del Colegio de Doctores y Licenciados de Madrid desde 1973 a 1976 , ocupándose de las tareas de tesorero y responsable del Boletín, según afirma en la respuesta a un cuestionario de la Revista de Educación con motivo del número extraordinario publicado en 1992 titulado «La Ley General de Educación veinte años después» (pp. 323-324). En su respuesta, por cierto, reconoce haber pecado en aquellos años, como el resto de los promotores de la Alternativa, de «optimismo ingenuo».

III Ibid., p. 5I.

II2 Ibid., p. 53. 
Todo apunta, y el mismo Bozal lo señala, a que «la enseñanza participaba [en aquel entonces] de un horizonte más amplio, general, en el que era evidente la convicción de un posible cambio radical, al menos en aquellos ámbitos no estrictamente económicos [...] que permitirían una transformación del país: la enseñanza, la cultura, los servicios...». De ahí que no valoraran «en su justa medida el peso específico de la Iglesia y del funcionariado -que no participaba en la actividad colegial (tampoco en la actividad sindical, por entonces incipiente) con la misma intensidad que los enseñantes de la privada-» y sobrevaloraran «la capacidad de movilización del Colegio» de Doctores y Licenciados. Una «capacidad» que fue, dice, "grande y llamativa», pero no suficiente ni sostenida durante un largo tiempo. La derrota de la Junta de Gobierno de dicho Colegio en las elecciones de 1976 indicaba cuál era la «situación real» y la fuerza tanto del subsistema educativo católico, en relación con la idea de escuela pública, como de los cuerpos de funcionarios docentes -sobre todo en la enseñanza media, donde no se veía con buenos ojos la reducción del bachillerato tras la reforma de 1970-, en relación con la propuesta de un ciclo único y un cuerpo único de enseñantes. Otras circunstancias, continúa Bozal, que explican que no se efectuara «una valoración correcta de la situación» permitiendo «la persistencia de espejismos que sólo se disolvieron años después» fueron el todavía «débil» arraigo de los sindicatos en el sector de la enseñanza -aunque sus reivindicaciones, una vez constituidos a partir de 1977 , fueran de orden más «laboral» que político- y el temor coactivo, en los primeros años de la Transición, a que un cambio en la enseñanza como el propuesto generara una mayor «inestabilidad política». Por último, cuando el PSOE ganó las elecciones en 1982, los nombramientos en el Ministerio de Educación

marginaron del esperado protagonismo a quienes habían elaborado la Alternativa. Una tímida reforma de la enseñanza [...] mantuvo en todo su vigor la doble red, estatal y privada, y olvidó, no sé si para siempre, el concepto de Escuela Pública ${ }^{\mathrm{II}}$.

Otro testimonio privilegiado, procedente de alguien, Ignacio Fernández de Castro, que no formó parte de los grupos promotores de las diversas alternativas, pero lúcido analista de lo que estaba sucediendo en la educación española en esos años $-\mathrm{y}$ en los posteriores hasta su fallecimiento en 20II-, puede ayudarnos a completar la valoración actual de las alternativas y del movimiento de enseñantes.

Ignacio Fernández de Castro fue uno de los fundadores del Frente de Liberación Popular (FLP) en la década de los cincuenta. Exiliado en París desde 1962 a 1970 vivió de modo presencial y directo la revuelta estudiantil de mayo del 68. Su vivencia e interpretación de la misma se recogió en un texto inédito, redactado en 1969-70, destinado a «contribuir a la destrucción del mito clase-obrera», con el título, suficientemente expresivo, de La clase obrera ba muerto. Reflexiones críticas sobre la clase obrera seguidas del ejemplo francés. La relevancia, a su juicio, de los acontecimientos de mayo del 68 derivaba de dos hechos: la presencia determinante de los estudiantes en la lucha de clases, algo inédito hasta el momento,

\footnotetext{
${ }^{113}$ Ibid., pp. 54-55.
} 
y el fracaso de su intento de despertar a la clase obrera para hacer la revolución. El intento revolucionario, dirá, fracasaría por el retraimiento de una clase obrera carente de objetivos revolucionarios o utópicos, presentes, sin embargo, en el movimiento estudiantil: la revuelta sería sofocada por las fuerzas del orden, incluidas, sobre todo, las organizaciones políticas y sindicales de izquierda ${ }^{\mathrm{II}}$. Estos hechos serían los que le hicieron tomar conciencia de la necesidad de estudiar las relaciones entre clases sociales, sistema productivo y educación, algo que llevaría a cabo, en relación con el sistema educativo español, en los años siguientes. Todo ello tras abandonar su «etapa de militante partidista de la revolución» para unirse al «movimiento asambleario» antifranquista y fundar un pequeño «equipo de estudios» (EDE) con el fin de «informarnos, publicar y relacionarnos con otros grupos y personas de la oposición»"

Los textos que nos interesan ahora son dos artículos publicados en Cuadernos de Pedagogía, en 1977 («El sistema educativo y el cambio político», escrito junto con Carmen de Elejabeitia) y en i980 («La vieja Ley de Educación»), así como la entrevista que aparece en la misma publicación (en 1981) con el título «La utopía como esperanza».

En el primero de ellos, tras sintetizar, a la altura de 1977 , los conocidos «puntos esenciales y comunes de los programas socialista y comunista para la etapa democrática que se abre», coincidentes con los de las alternativas, en especial la madrileña, prevé que

si la izquierda [...] va a basar su acción política sobre el fracaso de la Ley General de la Educación y a forzar la realidad de la «igualdad de oportunidades», a través de la exigencia de la escuela pública y gratuita (aun sin enfrentarse abiertamente a la enseñanza privada), y la ruptura progresiva de los condicionamientos económicos para el acceso a las enseñanzas superiores, al propio tiempo que apoyará y organizará el descontento y las reivindicaciones laborales del cuerpo enseñante, la derecha deberá responder a su clientela política potencial defendiendo la enseñanza privada y religiosa bajo el pretexto de la «sagrada libertad de los padres» de dar a sus hijos la enseñanza que deseen, manteniendo criterios de selectividad rigurosos que revaloricen los títulos superiores, aseguren su reserva a los hijos de las familias acomodadas y mejoren las condiciones de trabajo de estos profesionales fuertemente afectados por la inflación de estudios universitarios de estos últimos años ${ }^{116}$.

${ }^{114}$ Sobre la influencia de los sucesos del mayo francés del 68 en las ideas y la obra posterior de Fernández de Castro, véase Rogero AnAYa, Julio: «Recorrido por la vida y obra de Ignacio Fernández de Castro», Con-Ciencia Social, i4 (20Io), pp. 83-89 (pp. 84-85); Fernández de Castro, Ignacio: «La vieja Ley de Educación», Cuadernos de Pedagogía, 62 (1980), pp. 37-40 (p. 40), y CuAdernos DE Pedagogía: «Entrevista. Ignacio Fernández de Castro. La utopía como esperanza», Cuadernos de Pedagogía, 75 (198I), pp. $22-27$ (pp. 22-23).

in Rogero, Julio y López, Carlos: «Conversación con Ignacio Fernández de Castro», ConCiencia Social, I4 (2010), pp. 9I-II2 (pp. 96-98).

in De Elejabeitia, Carmen y Fernández de Castro, Ignacio (ede): «El sistema educativo y el cambio político», Cuadernos de Pedagogía, 34 (1977), pp. 25-3I (pp. 26 y 28). 
En otras palabras, «la izquierda marxista y obrera», renunciando a una ruptura decidida con la función asignada al sistema educativo en el modo de producción capitalista, de "producir fuerza de trabajo-mercancía para el mercado de trabajo [...] no plantea alternativas revolucionarias sino simplemente reformistas». La «única alternativa revolucionaria posible» tiene que basarse no en «un proceso de enseñanza y calificación», que es a lo que conduce todo intento de hacer real la igualdad de oportunidades, sino en «la consecución de que la fuerza de trabajo deje de ser mercancía, deje de tener valor de cambio, o, lo que es lo mismo, hacer desaparecer el trabajo asalariado». De seguir así,

si la izquierda no formula una alternativa global revolucionaria en la que la enseñanza tenga funciones y objetivos radicalmente distintos, se encontrará abocada a jugar a la demagogia desde la oposición, apoyándose en la insatisfacción permanente de las expectativas, y si llega a ocupar el poder dentro del sistema, deberá enfrentarse a ellas no para satisfacerlas, sino para recortarlas ajustándolas a una realidad que impone unos límites bien modestos a toda reforma ${ }^{\text {117}}$.

Mejor, concluye, «reconocerlo y asumirlo para no caer en un nuevo triunfalismo de izquierdas, tan destructivo y demagógico como el que hemos padecido ${ }^{\text {r18 }}$. Tres años después, en 1980, con la Constitución ya aprobada y advenida la nueva democracia con sus libertades sindical y política, Fernández de Castro constata, por un lado, el debilitamiento de la lucha por parte de los enseñantes, orientados hacia las reivindicaciones sindical-laborales; de las asociaciones de padres de alumnos y de vecinos de los barrios y municipios -estas últimas prácticamente inexistentes-, y de los estudiantes, salvo ante problemas concretos como la selectividad. Y, por otro, la caída de la combatividad obrera y la colaboración de los partidos y organizaciones de masa de izquierda con las fuerzas de la derecha y del centro para asentar la democracia, que ha supuesto, dice, una tregua social y una renuncia de hecho a presentar y apoyar una alternativa revolucionaria. Vuelve a insistir en una izquierda que se reduce a ofrecerse como eficaz gestora de la crisis, en las frustraciones del desarrollo de un sistema dirigido a acrecentar los niveles de consumo capitalistas y en la conversión de la educación en mercancía con un valor de cambio en beneficio del capital. Y forzado a buscar alguna de las causas explicativas de esta actitud, Fernández de Castro menciona el temor a un golpe autoritario -temor con base real, por lo que poco después se vería - y la pérdida de todo atractivo y capacidad movilizadora de los modelos del Este y su mundo, es decir, del modelo soviéticon'

Esta referencia al modelo comunista merece un comentario, siquiera para compararla con la influencia que el modelo educativo soviético tuvo en determinados grupos sindicales y políticos obreros antes y durante la Guerra Civil.

${ }^{117} \quad$ Ibid., pp. 30-31.

ir8 Ibid., p. 3 I.

19 FernándeZ de CASTro, Ignacio: «La vieja Ley de Educación», op. cit., pp. 38-4o. Tesis similares, algo más desarrolladas y plegadas a la realidad, las mantendría un año después en la mencionada entrevista publicada en el n. ${ }^{\circ} 75$ de 1981 de Cuadernos de Pedagogía. Su conclusión era terminante: no había alternativa creíble, solo quedaba «la utopía como esperanza». 
¿Existió en la España de los años setenta y ochenta un modelo externo de referencia similar al que en los años veinte y treinta constituyó el sistema educativo soviético para el movimiento obrero y sindical? Repasando las páginas de los primeros años de Cuadernos de Pedagogía, la revista más emblemática del movimiento de enseñantes, pueden hallarse artículos sobre la educación en el Chile de Allende, en Portugal tras la «Revolución de los claveles», China, Cuba o sobre las políticas educativas de algunos municipios o regiones regidas, en Italia, por partidos de izquierda. Pueden hallarse también referencias a autores, planes o reformas anteriores, tanto de España (Institución Libre de Enseñanza, Segunda República, plan del CENU, etc.) como fuera de ella (plan Langevin-Wallon, movimiento de la Escuela Nueva), o coétaneos (movimiento de la «educación liberadora» $)^{120}$, a la búsqueda de una tradición en la que insertar las «alternativas» o propuestas en favor de un nuevo sistema y formas de educación. Sin embargo, las referencias a la educación en la URss, aun existiendo -aunque más a pedagogos y psicólogos como Suchodolski, Luria o Vigotski que a las realizaciones del sistema educativo soviético-, no son comparables, tanto desde un punto de vista cuantitativo como cualitativo, a las que pueden encontrarse en libros y revistas de los años 20 y 30. Simplemente, la escuela soviética había dejado de ser, para el movimiento obrero y los partidos cercanos al mismo, el principal modelo o referente a tener en cuenta.

Esta cuestión está relacionada tanto con la nueva posición eurocomunista del PCE como con la influencia del movimiento, en sus inicios, de la unidad europea. Nada ejemplifica mejor el cambio de perspectiva que el debate planteado en 1977 en las páginas de la revista Teoría y Práctica, editada por EDE, la mencionada sociedad de estudios dirigida por Ignacio Fernández de Castro. El artículo, firmado por H. R. (un suscriptor de la revista que entonces se hallaba en la Universidad Karl Marx de Leipzig, en la RDA), inserto en la sección de «Materiales para debate», llevaba el provocador título de «El “desierto cultural” soviético». En síntesis, H. R. se refería a las posiciones públicas, claramente contrapuestas, de dos relevantes miembros del PCE en relación con el sistema educativo de la Unión Soviética y países afines. Una, de índole negativa -«desierto cultural»- sostenida en las páginas de la revista Triunfo (número 7or) por Manuel Azcárate -«que había sorprendido por su crudeza a un sector del marxismo español y de forma muy

120 El movimiento de la «educación liberadora» (Reimer, Goodman, Illich, Freire, Milani...) se veía, en I975, como «una respuesta» a «la sociedad científico-técnica que nos ha tocado vivir», análoga a como la Escuela Nueva lo había sido a «la sociedad industrial». Constituía «una teoría nueva del mundo, de la vida y del hombre surgida del análisis crítico de nuestra sociedad a la luz de una síntesis superadora de cristianismo y marxismo». Hasta tal punto que, quienes así hablaban, no dudaban en establecer un paralelismo entre el papel desempeñado por el Instituto «Jean-Jacques Rousseau» de Ginebra en el movimiento de la Escuela Nueva y el del Centro Intercultural de documentación (CIDOc) de Cuernavaca, fundado en I96I, en el movimiento de la «educación liberadora» [PASTOR, Estanislao y Román, José M.a: «El movimiento de la educación liberadora», Cuadernos de Pedagogia, 5 (1975), pp. 32-34 (p. 32)]. Los términos «concientización» (Freire) y «desescolarización» (Illich) fueron, en aquellos años, «dos conceptos muy en boga en amplios sectores educativos» [Silva, Alberto, "¿Por qué un dossier Freire/Illich ahora?», Cuadernos de Pedagogía, 7-8 (1975), pp. 2-3 (p. 2)]. 
especial a la militancia comunista»-, centraba su atención en el «carácter monolítico» de dicha educación, la «esclerosis» o «debilidad ideológica» provocada por «la falta de libertad en la enseñanza y la vida cultural, y «la degradación» de una «formación impartida» de acuerdo con una «doctrina oficial» $»^{121}$. Frente a ella, el destacado dirigente de Comisiones Obreras Marcelino Camacho se refería, poco tiempo después, y también públicamente, al sistema de educación soviético como «una de las tres direcciones punta» de la política educativa de la URss, a la luz de sus resultados en relación con la escolarización y el nivel educativo alcanzado por la población.

Más allá de las cuestiones a las que el debate afectaba -la posición del PCE en relación con la URss, la posible «complementariedad» entre ambas valoraciones, la oposición de Marx a un Estado educador en la Crítica al proyecto del programa del Gotha-, detrás de dicha confrontación se hallaba la diferente perspectiva de un líder obrero atento no solo a lo ideológico, sino también a los espectaculares resultados educativos y científicos de la URSs, en comparación con la situación educativa de la clase obrera en España -cuyas deficiencias había sufrido en su propia carne-, y de un líder político universitario e hijo de diplomático, para el que la ausencia de libertad en la enseñanza y la imposición de una «doctrina oficial» eran dos aspectos fundamentales a valorar más allá de los resultados objetivos, cuantitativos, de un determinado sistema educativo.

En este epígrafe, hemos analizado, hasta ahora, la valoración desde posiciones críticas -institucional (CNT) una e individual (Fernández de Castro) otra, ambas marginales- acerca de lo que supusieron en su momento las «alternativas», el movimiento de enseñantes y su evolución posterior. Entre las valoraciones retrospectivas efectuadas por algunos de sus protagonistas destaca, además de las ya referidas, la del que fue presidente del Colegio de Doctores y Licenciados de Madrid desde enero de 1974 a febrero de 1979, Eloy Terrón ${ }^{122}$.

En una entrevista realizada en noviembre de 1976 , tras referirse al origen y sentido de la Alternativa aprobada en enero de dicho año, ya indicaba algunos de los problemas que su aplicación iba a encontrar. Para Eloy Terrón, desde una posición más realista, y desde luego más lúcida que la de sus jóvenes promotores -contaba entonces 57 años-, la Alternativa era «un simple programa de intenciones que, a primera vista, no es fácil que se convierta en el marco del sistema educativo del país». Es más, «los enseñantes estaban seguros, cuando se inició la elaboración de la Alternativa, que nuestro país avanza irrevocablemente hacia una democracia burguesa de tipo occidental» y, por tanto, hacia «una democracia capitalista industrial», una sociedad plural en la que la «acción» de «la escuela y

${ }_{121}$ H. R.: «Materiales para debate. El “desierto cultural” soviético», Teoría y Práctica, 6 (1977), pp. $87-96$.

${ }_{122}$ Eloy Terrón, campesino y minero en su juventud, autodidacta, marxista afín al PCE, profesor de filosofía, sociólogo y antropólogo, fue asimismo presidente de los Colegios de Doctores y Licenciados de España de 1974 a 1983, del Club de Amigos de la Unesco y de la Fundación r. ${ }^{\circ}$ de mayo de Comisiones Obreras. Las obras de y sobre Eloy Terrón están accesibles, gracias a Rafael Jerez Mir, en http://ahf-filosofia.es/?page_id=268. 
los enseñantes» no iba a ser «determinante» frente a la «lucha publicitaria, desatada por la rivalidad comercial y la pluralidad ideológica partidista». En efecto, añadía, esa

sociedad democrática, en que estamos ya irremisiblemente, se caracteriza por un potente pluralismo ideológico, consecuencia de que cada clase social [...] y cada partido se esfuerza por difundir e imponer su ideología, su concepción de la realidad. Sin olvidar de que al lado y entremezclada con la ayuda ideológica ejerce su enorme poder la publicidad comercial, cargada también de insinuaciones ideológicas.

De ahí que «el objetivo» más profundo de la Alternativa, si quería dársele algún sentido, solo pudiera ser el de «conseguir un sistema de enseñanza que ponga a los jóvenes en condiciones de entender la complejidad de relaciones tecnológicas y sociales de la sociedad industrial para orientarse y ser capaces por sí mismos de elegir libremente su destino». De este modo, concluía, «considerada políticamente, la Alternativa pretende satisfacer» tanto «las necesidades educativas de la democracia industrial capitalista, a la que vamos directamente», como las de «la democracia avanzada o etapa de transición hacia el socialismo» como ideal u objetivo ${ }^{123}$.

Esta visión, entre realista y lúcida, la desarrollaría y completaría en escritos posteriores al llamar la atención sobre algunas de las características de esa sociedad democrática que estaba ya ahí, y que no todos supieron o quisieron ver, cediendo a ellas: el consumismo irreflexivo, la creación de necesidades superfluas, la relación no duradera con las cosas y, en definitiva, en palabras del mejor conocedor de la obra de Eloy Terrón, «una concepción puramente mercantil de la personalidad, basada en la sustitución del ser por el tener ${ }^{\text {124 }}$. Los efectos combinados de esa «nueva forma de religión» que era la publicidad directa o indirecta y de «los medios de comunicación de masas» y «la industria de la cultura»-más bien, decía, «subcultura»-, en las sociedades capitalistas, industriales y democráticas, hacían «que bien pudiera hablarse» de ellas «como sociedades informadas, sobreinformadas, casi científicamente deformadas» $»^{125}$. Un exceso de información que, al no poder ser interiorizado, clasificado y ordenado, de poder constituir un «elemento insustituible de racionalidad», devenía en «factor de desorganización y de envilecimiento de los que la reciben, de degradación de las conciencias individuales» ${ }^{126}$.

$\mathrm{Su}$ «alternativa» u opción no marginal ante ese futuro, ya presente, la desarrollaría en diversas ocasiones. Se trataba de una alternativa dirigida a educar no

${ }_{123}$ «Una enseñanza democrática solo puede darse en una sociedad democrática», en Enseñanza: debate público, op. cit., pp. 283-29I (pp. 286-289).

${ }^{124}$ Jerez Mir, Rafael: La visión de Eloy Terrón sobre la educación para la democracia en la España industrial capitalista y democrático-burguesa, Madrid, Club de Amigos de la Unesco, 2006, p. I5. Salvo que se diga otra cosa, las citas y referencias que siguen se toman de este trabajo.

125 Terrón, Eloy: «Familia y educación en un contexto de clase obrera», en Fernández EnGuita, Mariano (ed.): Marx y la sociología de la educación, Madrid, Akal, 1986, pp. 393-409 (pp. 399-400).

${ }^{126}$ Ibid., p. 4 OI. 
a «las minorías dirigentes», sino «a las masas, a los hijos de los trabajadores asalariados (con mucho la parte más numerosa de la población), a los hijos de la pequeña burguesía (clase media baja)», lo que exigía «una educación nueva» ${ }^{127}$, basada en la unión de padres y profesores; el «liderazgo»; la orientación de un profesorado «humanista, racionalista y demócrata» ${ }^{128}$, y «un conocimiento científico, suficientemente riguroso para constituir la base de las libertades necesarias a los hombres de las sociedades industriales capitalistas»; es decir, para hacer de la educación un proceso «liberador» de las constricciones y formas de sujeción y control propias de las mismas ${ }^{129}$.

El juicio o valoración posterior de Eloy Terrón sobre la Alternativa madrileña, y de modo general sobre las restantes, efectuado en 1985 en una entrevista concedida a la revista Trabajadores de la Enseñanza de cc. oo., no reflejaba añoranza, sino realismo:

Esa experiencia inicial, decía, tan viva, se anuló por completo; caímos en un positivismo, un desencanto, que atribuyo a que los jóvenes que más lucharon consiguieron la estabilidad, el funcionariado. La Administración tuvo un acierto: conceder esas oposiciones restringidas y dispersar por toda España el núcleo tan vivo que había en Madrid. Con esa dispersión se acabó todo ${ }^{130}$.

Por otra parte, aspectos concretos de la Alternativa como la renovación pedagógica y la gestión democrática de los centros docentes se habían visto dificultados por la política burocratizadora del PSOE, «más empeñado en dar normas de cómo los profesores deben de actuar, [...] que en "despertar" su "inquietud" y "estimularlos"», y también por el recorte impuesto a las actividades de las asociaciones de padres. Por último, señalaba Eloy Terrón en dicha entrevista, «se ha abandonado» el «campo» de los colegios profesionales como organismos de debate y propuesta en el ámbito de la enseñanza:

Hubo celos de que no se desarrollaran bien los sindicatos si existían los colegios; FETE se opuso muy radicalmente porque veía que no daba margen al desarrollo de los sindicatos, luego vimos que la sindicación no mejoró porque este es un sector diferente ${ }^{13 t}$.

En síntesis, constataba Eloy Terrón, «entre los años 76, 77 y 78, la Alternativa empezó a caer en desuso». En efecto, ni se discutió a nivel nacional, como era su destino y sentido -quizás también porque surgieron otras a nivel regional

${ }_{127}$ Terrón, Eloy: Sobre el futuro de nuestro colegio, Madrid, texto mimeografiado, junio de 1980, pp. 2 у 9-Іо.

${ }_{128}$ Terrón, Eloy: Educación y sociedad, Madrid, texto mimeografiado, 1982, pp. 5-7.

${ }^{129}$ Terrón, Eloy: «La enseñanza escolar como vía de liberación», en Foro de Ciencias y Letras, Granada, 198I, pp. 97-IO4 (p. 100). (p. 4).

130 Entrevista de Pascual Sicilia a Eloy Terrón, Trabajadores de la Enseñanza, 24 (1985), pp. 4-5 ${ }^{131}$ Ibid., p. 5 . 
y provincial o formuladas por los «nuevos» partidos políticos y sindicatos-, ni se avanzó en los temas más conflictivos -reforzamiento de la educación pública frente a la privada, cuerpo único de profesores, estatuto docente- o, cuando se hizo -ciclo único, formación del profesorado-, fue de forma parcial e insatisfactoria. Además de los aspectos señalados -funcionarización de los profesores no numerarios; burocratización, absorción y control por los partidos y sindicatos, en competencia entre sí, de la representación del profesorado-, la Constitución de 1978 recogía en su artículo 27 las propuestas de los partidos y de la Iglesia católica en materia de enseñanza, entremezcladas, eso sí, con otras formuladas por los partidos de izquierda. Una combinación que hacía constitucionalmente inviables algunos de los elementos básicos de la Alternativa madrileña o de otras. Las críticas de Eloy Terrón a la política y comportamiento del PsOE se extendían, en cuanto al aspecto formativo, también al PCE:

Todos los esfuerzos de los intelectuales del Partido [comunista] se aplicaban a la lucha política para conseguir más votos y más diputados en las elecciones generales, más diputados en las elecciones autonómicas y más concejales en las municipales. A eso se reducía la actividad política del Partido, en competencia con los demás partidos políticos. Y, para luchar en condiciones más semejantes a las de otros partidos políticos, se disolvió la organización básica, en células, y se crearon las agrupaciones, que dejaron a los militantes reducidos a esporádicos contactos y reuniones con compañeros desconocidos, o rara vez conocidos.

¿Cómo se formaban esos militantes, puesto que se carecía de medios de comunicación adecuados (periódicos, revistas, escuelas del partido)?; y, si nadie les formaba, ¿qué mensaje podían llevar los militantes a la sociedad? Un destacado dirigente de un sindicato (ccoo) declaraba en público que él no necesitaba pasquines ni folletos, porque, en llegando a una fábrica, pegaba dos gritos y ya tenía a los trabajadores movilizados y dispuestos para lo que fuese necesario.

A los militantes españoles el PCE no se les estimuló para que imaginasen cómo debía ser la nueva sociedad: ideal, racional, pacífica, perfecta. Salvo que se considere un estímulo la Historia del Partido Comunista de la URSS (en la que colaboró -parece que estrechamente- J. Stalin), que fue enviada en un tomito camuflado como un «Episodio» de Benito Pérez Galdós. A los dirigentes del partido no se les ocurrió nada peor ${ }^{132}$.

\section{Coda}

En esta historia hay un antes y un después de la Guerra Civil y el franquismo. En el período anterior, el movimiento obrero oscila entre: a) la configuración de una red cultural y escolar propia, rechazando la de origen estatal y la intervención desde el poder público para establecer su modelo educativo; b) el seguimiento o, por el contrario, el recelo o rechazo del modelo establecido en la uRss; y c) la

${ }^{132}$ Terrón, Eloy: Estado y conciencia en la sociedad de clases. (Un libro inédito de Eloy Terrón de 2002), Madrid, febrero de 20I2, p. 24I. Edición a cargo de Rafael Jerez Mir. Accesible en http://ahffilosofia.es/wp-content/uploads/20I2_Estado_y_conciencia_en_la_sociedad_de_clases.pdf. 
preferencia por el ideario educativo anarquista-libertario o por el socialista reformista o revolucionario. La Guerra Civil supondría tanto la posibilidad de llevar a la práctica ambos proyectos como su desmantelamiento y aniquilación.

El resurgir del movimiento obrero a partir de los años cincuenta se hizo en circunstancias -ausencia de libertades sindicales, sociales y políticas- y sobre bases -obrero cristianas, comunistas y anarquistas- muy diferentes a las del período anterior. Su configuración sirvió de referente al incipiente movimiento de enseñantes, que en el sector privado o en el estatal -los no numerarios- trabajaban sometidos a normas y condiciones laborales precarias. Sus reivindicaciones básicas giraban en torno a los conceptos de libertad, participación y escuela pública. Las condiciones de trabajo y las acciones llevadas a cabo para su mejora -huelgas, asambleas, encierros, coordinadoras, etc.- les condujeron a tomar conciencia como sujeto colectivo transformador, y a formular, desde perspectivas sociopolíticas, diferentes alternativas a un sistema educativo incapaz de llevar a cabo sus propios objetivos reformistas.

Si la derrota del bando republicano en la Guerra Civil impidió configurar un sistema educativo acorde con las propuestas e ideas surgidas en el movimiento obrero, la implantación de un régimen formalmente democrático en 1978 supondría, paradójicamente, el declive, debilidad o disolución de las propuestas educativas rupturistas o radicalmente transformadoras. Algunas de las causas que explican este hecho -funcionarización de los PNN, canalización de las reivindicaciones laborales a través de los nuevos sindicatos y partidos, etc.- han sido ya expuestas. Otras podrían añadirse:

- No se partía en 1978 -con un subsistema educativo católico reforzado durante el franquismo y la Transición; con sindicatos todavía muy débiles; y con un nuevo régimen democrático «vigilado»- de una situación equiparable a la de 1936.

- Se iba hacia una sociedad capitalista, del mercado, el consumo, el espectáculo y el entretenimiento, conformada mentalmente por la publicidad, el consumismo y la sobreinformación banal en la que la educación, y con ella los sujetos individuales o colectivos, pasaban a convertirse en mercancía. En síntesis, «la democracia» había encontrado «su pareja: el mercado» ${ }^{133}$.

- $\mathrm{Al}$ aceptar y firmar la Constitución de 1978 y, en concreto, su artículo 27, la izquierda social y política renunciaba a llevar a la práctica no ya su proyecto revolucionario guerracivilista, sino incluso el reformista-republicano de I931.

- Asimismo, al renunciar dicha izquierda social y política -en este caso por voluntad propia- a crear un subsistema educativo acorde con sus planteamientos ideológicos, se incapacitaba para conformar ese profesorado «humanista, racionalista y demócrata», de cuya necesidad hablaba Eloy Terrón en 1982, que diera vida a dicho subsistema.

${ }_{133}$ RozADA, José María: «Las reformas y lo que está pasando. (De cómo la democracia encontró su pareja: el mercado)», Con-Ciencia Social, 6 (2002), pp. 15-57. 
En este contexto, la situación en el momento de escribir estas líneas no debe producir extrañeza. Han sido necesarios casi diez años de crisis económica y «recortes» en derechos sociales -los educativos entre ellos- y tres décadas de aplicación de políticas más o menos conservadoras y de fortalecimiento del statu quo para que hayan surgido de nuevo una serie de movimientos sociales para la defensa y mejora de la educación pública, bajo la denominación de mareas, redes, foros, coordinadoras, colectivos, plataformas, etc., a los que se han sumado lo que queda de grupos fundados en los años setenta, como el MCEP o los movimientos de renovación pedagógica (MRP), la federación de padres y madres del sector público, partidos considerados de izquierda y sindicatos de enseñanza «de clase» o de estudiantes. Tampoco debe extrañar que, como reacción a la Ley Orgánica para la Mejora de la Calidad Educativa (LOMCE) y a los mencionados «recortes», dichos colectivos hayan llegado a suscribir, en 20I5, un «Documento de bases para una nueva política educativa. Acuerdo social y político educativo» que puede considerarse la última versión, por el momento, de ese programa educativo tantas veces formulado por los movimientos populares, obreros o sindicales ${ }^{134}$. Una versión surgida de una simbiosis entre movimientos sociales y profesorado alimentada por la reacción de quienes se han visto negativamente afectados por determinadas políticas sociales y educativas. Su análisis queda fuera de este texto. Y su futuro, aunque incierto, permanece abierto.

${ }^{134}$ Accesible en https://porotrapoliticaeducativa.org/project-type/documento-de-bases-parauna-nueva-ley-de-educacion-acuerdo-social-y-politico-educativo/. 